\title{
Sprachbiographien deutscher Emigranten. Die ,Jeckes“ in Israel zwischen Verlust und Rekonstruktion ihrer kulturellen Identität
}

\begin{abstract}
Auf der Grundlage von narrativen autobiographischen Interviews mit rund 200 jüdischen Emigrant/inn/en, die in den 1930er Jahren aus deutschsprachigen Ländem nach Palästina/Israel flüchteten, und weiteren Audioaufnahmen mit der 2. Generation werden die Gründe für Bewahrung oder Abwendung von der deutschen Sprache sowie die Veränderungen sprachlicher Kompetenzen in Verbindung mit der sozialen und kulturellen Integration im neuen Land untersucht, das (als „Land der Väter") aus historischen und ideologischen Gründen totale Akkulturation und Integration erwartete. Vor der Folie der faktischen und psychologischen Schwierigkeiten der gesamten Migrationsgruppe werden zunächst die Folgen des erlittenen Bruchs am Beispiel der (Sprach-)Biographien von fünf besonders erfolgreich in die hebräischsprachige Gesellschaft integrierten Persönlichkeiten der 1. Generation dargestellt. Dabei wird von der Annahme ausgegangen, dass die von ihnen noch ca. 60 Jahre nach der Emigration thematisierten Probleme eines erzwungenen Identitätswechsels generelle Probleme speziell dieser, aber z.T. auch, universell übertragbar, aller Migrationen sind. Ein weiterer Teil widmet sich anhand von vier Fallstudien der Frage, welche Faktoren für die Akzeptanz oder Ablehnung der deutschen Sprache und Kultur des Elternhauses bei den bereits in Israel geborenen und spätestens seit dem Schuleintritt vollständig hebräisch-is raelisch sozialisierten Kindern eine Rolle gespielt haben und wie sich die damaligen Identitätsprobleme auf ihre heutige Sprachkompetenz im Deutschen und auf die Einstellung zum Herkunftsland der Eltern ausgewirkt haben. Der Schwerpunkt der Analyse liegt bei beiden Generationen auf dem Zusammenspiel individueller Erfahrungen, kollektiver Erwartungen und den daraus neu abgeleiteten weltanschaulichen und kulturellen Orientierungen für die (Re-)Konstruktion der persönlichen Identität und ihren im weiteren Leben erfolgenden Modifikationen. Die Untersuchungsperspektive folgt weitgehend der retrospektiven Selbsteinschätzung der Gesprächspartner/innen, die in der narrativen ,Selbstinszenierung " der Interviewsituation wesentlich mit beeinflusst ist von ihrem subjektiven Selbst-Verständnis, dem zu vermitteln versuchten Image, aber auch der Rolle als Zeitzeuge, stellvertretend für eine Schicksalsgemeinschaft bzw. Generation.
\end{abstract}

\section{Einführung in Hintergründe und Besonderheiten des Korpus „Emigrantendeutsch in Israel“}

\subsection{Die ,Jeckes"}

"Jeckes" wurden die deutschen Hitler-Flüchtlinge vom Jischuw, der damals überwiegend aus Osteuropa stammenden jüdischen Gemeinschaft in Paläs- 
tina genannt. ${ }^{1}$ Diese Bezeichnung war in den 1930er Jahren bestenfalls spöttisch gemeint, die Betroffenen empfanden sie meist als Schimpfwort, und ganz besonders für die 2. Generation war es das wirksamste Mittel, sie als Kinder zu beschämen und zu beleidigen. ${ }^{2}$

Der folgende Artikel wird sich va. damit auseinandersetzen, wie eng die Integration und Akkulturation dieser Migrantengruppe mit dem Sprach(en)problem affiliert war. Dabei werden z.T. ganz spezielle, singuläre Probleme aufgrund einer einmaligen historischen Konstellation zu erörtern sein, aber auch Phänomene, die für jede Migration, die mit Sprach- und Kulturwechsel verbunden ist, Gültigkeit besitzen. Die Unterschiede gehen u.a. darauf zurück, dass die bislang im Mittelpunkt der Forschung stehenden Arbeitsmigranten meist einen niedrigen sozialen Status, schlechte Ausbildung und häufig nur mangelhafte Kenntnisse der Standardsprache und der (Hoch-) Kultur ihrer Herkunftsländer aufweisen; des Weiteren ist ihr Aufenthalt im Zielland oft zunächst zeitlich begrenzt geplant und sie besitzen daher wenig Motivation, sich dessen Sprache auf einem höheren Niveau anzueignen und sich kulturell zu integrieren. Die jüdischen Zwangsemigranten der Nazizeit hingegen waren in der Regel (sehr) gebildet oder zumindest bildungsorientiert und hatten überwiegend eine starke emotionale, identitätsprägende Bindung an die Kultur ihres Geburtslandes, ${ }^{3}$ mit der sie aber aufgrund der Umstände vollständig brechen wollten oder zumindest sollten; von ihnen wurde erwartet, sich ihre, ,eigentliche“ Herkunftssprache Hebräisch bzw. Iwrit und die hebräisch-jüdische Kultur möglichst rasch und möglichst ebenso gut anzueignen. Gerade dies jedoch fiel der Mehrzahl der deutschen Juden besonders schwer. Die wenigsten von ihnen hatten Hebräischkenntnisse, die über einige Gebete hinausgingen, und sie waren viel mehr auf nur eine Sprache, nämlich ihre deutsche Muttersprache, fixiert als die mehrsprachig sozialisierten und von Kindheit an mit der hebräischen Sprache und jüdischen Tradition vertrauten osteuropäischen Juden, die in der Aufnahmegesellschaft in Erez Israel den Ton angaben.

Die jüdische Bevölkerung im Britischen Mandatsgebiet Palästina wird vor 1933 auf ca. 200.000 Menschen geschätzt; davon kamen weniger als

\footnotetext{
Die Herkunft der Bezeichnung ist nicht genau geklärt; in jedem Fall bezog sie sich ursprünglich auf die „durch die Akkulturation an die deutsche Umwelt geformten Charaktereigenschaften $^{\text {"s }}$ speziell der deutschen Juden (aus der Perspektive des stärker der jüdischen Tradition verhafteten osteuropäischen Judentums) und mutierte in Erez Israel zunächst zur Bezeichnung eines „umständlichen Zeitgenossen, der sich den Erfordernissen des Alltags verschließt" (Diner 2005, S. 110 f.), bevor sie heute eher positiv für Zuverlässigkeit, Pünktlichkeit, Ordnungsliebe steht. Zu den den Jeckes zugeschriebenen Eigenschaften vgl. auch Betten (2011c, S. 60).

2 Vgl. dazu Interview-Belege von Tom Lewy in Betten (2010, S. 34-43); ferner Betten (2011b, S. 222 f.) mit dem Erklärungsversuch von Ze'ev Walk: „ein mensch sehr pedantisch und nicht sympathisch - ein mensch das kann man nicht gut äh to live with him." (Zu Ze'ev Walk vgl. hier die Bsp. 13 und 15).

Vol. genauer Anmerkung 36 .
} 
3.000 aus dem deutschsprachigen Raum. Die nach Hitlers Machtergreifung einsetzende Einwanderung aus Deutschland und den später annektierten Nachbarländern, die so genannte 5. Alija, war die erste Masseneinwanderung. Da die Briten die legale Einwanderungsrate immer stärker limitierten, schwanken die Zahlen der bis 1940 ins Land Gekommenen (darunter auch viele Illegale und daher nicht amtlich Erfasste) zwischen 50.000 und 70.000. ${ }^{4}$

Die Lebensbedingungen der deutschsprachigen Migranten der 1930er Jahre unterschieden sich je nach Einwanderungsdatum, d.h. der sich ständig verschärfenden politischen Lage und den Schikanen der nationalsozialistischen Regierung und den daraus resultierenden traumatischen Erfahrungen vor und bei der Ausreise/Flucht, sowie nach Alter, Ausbildung, sozialem Status bei der Emigration und deren Vorbereitung ganz erheblich voneinander. ${ }^{5}$ Im gleichen Maße unterschieden sich die Auswirkungen dieser Vorgeschichten auf den Neuanfang in Erez Israel. Nur wenige konnten Teile ihrer Habe mitnehmen, die Mehrzahl kam mit nichts als dem nackten Leben; ebenso konnten nur wenige ihre alten Berufe weiter ausüben (in der Anfangszeit z.B. Ärzte, bis es eine Ärzteschwemme gab), die meisten mussten froh sein, wenn sie nach Jahren härtester Arbeit als Hilfsarbeiter, Maurer, Plantagenarbeiter, Busfahrer, Vertreter, Kellner/innen, Putzfrauen etc. später nochmals in Berufen Fuß fassten, die ihrer Vorbildung einigermaßen entsprachen. Aber auch die mentale und die praktische Vorbereitung auf das neue Land spielten eine entscheidende Rolle für die Eingliederung bzw. die Bereitschaft, bisherige Lebenspläne und -gewohnheiten völlig umzustellen und eine ganz neue Identität anzunehmen. Bei Religiösen und engagierten (meist noch jugendlichen) Zionisten war eine positive innere Einstellung zu diesen einschneidenden Lebensveränderungen eher zu erwarten als bei der Mehrheit der assimilierten älteren Einwanderer, die va. vor Hitler geflohen waren, aber weder durch ein gewisses Maß an Hebräischkenntnissen (wie bei den Religiösen) noch durch den glühenden Vorsatz, durch ihren vorbehaltlosen Arbeitseinsatz unter schwierigsten Bedingungen am Aufbau des Landes und einer neuen Gesellschaftsform mitzuarbeiten, auf das, was sie erwartete und was von ihnen erwartet wurde, vorbereitet waren. Wer dazu bereit war, ging oft aus freien Stücken in einen Kibbuz (viele jedoch nur notgedrungen) oder versuchte sich mit Gleichgesinnten in einer kooperativen Siedlungsform (z.B. einem Moshav) in der Landwirtschaft. In der Stadt musste sich hingegen jeder selbst durchschlagen. ${ }^{6}$

\footnotetext{
${ }_{4}^{4} \quad$ Mit einer genaueren Aufschlüsselung und Quellenhinweisen siehe Betten (2011c, S. 64f.); für die Einwanderung nach der Staatsgründung 1948 siehe Śegev (2008, S. 133 ff.); zum Verhältnis des Deutschen zu anderen Sprachen in Israel va. seit den 1960er Jahren siehe Ben-Rafael (1994, S. 191 ff.), zur heutigen Sprachsituation und Sprachenpolitik Shohamy (2005). Vgl. dazu Benz (Hg.) (1996) und Weinzierl/Kulka (Hg.) (1992).

In den Bänden Betten (Hg.) (1995) und v.a. Betten/Du-nour (2004) sind die Vielfalt der Lebensbedingungen und die unterschiedlichen Reaktionen der Immigranten darauf leitendes Prinzip für die Themenauswahl aus den Interviews.
} 
Da es die Ächtung der deutschen Sprache und Kultur in der Öffentlichkeit unmöglich machte, die an sie gebundenen Kompetenzen weiterhin zu pflegen und beruflich zu verwerten, ${ }^{7}$ wurden viele auf Dauer wirtschaftlich ins Abseits gedrängt und erholten sich von diesem sozialen Abstieg nicht mehr. Diese Umstände führten vielfach auch zu bleibenden Ressentiments der Jeckes gegenüber den russisch-polnischen Juden, die im Jischun politisch und gesellschaftlich das Sagen hatten und das (notgedrungene) Festhalten vieler Jeckes an der deutschen Sprache in den Anfangsjahren heftig attackierten. ${ }^{8}$ Die bereits im Land geborenen Kinder, genannt Sabres (vgl. Kap. 3), verstanden die Herkunft dieses Konflikts, der die Akkulturation ihrer Eltern zusätzlich belastete, jedoch bereits nicht mehr und empfanden die oft ablehnende Haltung ihrer Eltern gegen Juden aus osteuropäischen Ländern sogar als ,rassistisch ${ }^{c c}$. - Bessere Integrations- und Akkulturationschancen hatten natürlich jüngere Einwanderer, die noch nicht beruflich für sich und Familienangehörige sorgen mussten, sondern sich als Schüler oder Studenten auf die Anforderungen des neuen Landes noch vor der Gründung einer eigenen Existenz einstellen und ihre Identitätsentwürfe danach ausrichten konnten. Allerdings hatten diese Jugendlichen, wenn sie mit der so genannten Jugendalija ohne Eltern eingewandert waren, oft Traumata zu bewältigen, und auch der kollektive Anpassungs- und Erwartungsdruck lastete gerade auf ihnen häufig besonders schwer, worüber noch zu sprechen sein wird. ${ }^{10}$

\subsection{Zum Untersuchungskorpus und zum Erkenntnispotenzial der Beispielauswahl}

In einem Projekt von 1989 bis 1994, ${ }^{11}$ nochmals ergänzt $1998,{ }^{12}$ wurden ca. 200 deutschsprachige Emigranten der 1. Generation in ungesteuerten

Zu der Ächtung des Deutschen aufgrund der politischen Ereignisse kam noch der generelle Druck v.a. in der vornationalen Phase, aber auch während der neuen Masseneinwanderungen aus verschiedensten Regionen und Kulturkreisen nach der Staatsgründung 1948, das Hebräische als identitätsstiftende Nationalsprache durchzusetzen und daneben keine Sprachen der Diaspora zuzulassen: Vgl. Du-nour (2000a, S. 210 ff.), Ben-Rafael (1994, passim), ferner Shohamy (2005) mit Vergleichen zur heutigen Situation.

8 Über die Animositäten zwischen dem Jischuw und den Neueinwanderern aus Mitteleuropa informieren von der hier zitierten Literatur auch Rosenthal (2006, S. 233 f.) und, aus eigener Erfahrung sprechend, Bar-On (2004, S. 12 ff.). Vgl. auch Textbeispiel 4.

$9 \quad$ Mit Beispielen aus den Interviews vgl. u.a. Betten (2007b, S. $110 \mathrm{ff}$.).

10 Allgemeine Informationen über die deutschsprachigen Juden in Israel vermitteln z.B. Erel (1983), Zimmermann/Hotam (Hg.) (2005), Betten (2007a) und Maiwald (2008).

11 DFG-Projekt von Anne Betten, unter anfänglicher Mitarbeit von Kristine Hecker (Bologna), später von Miryam Du-nour (Jerusalem). Mit Textausschnitten und Analysen siehe Betten (Hg:) (1995) und Betten/Du-nour (Hg:) (2000) sowie Betten/Du-nour (2004). Die vollständigen Tonaufnahmen mit (dokumentarischen) Zusatzmaterialien sind zugänglich über das IDS Mannheim/Deutsches Spracharchiv (DGD 2.0), http://dgd.ids-mannheim.de, Korpus IS.

1222 Interviews mit ehemaligen Österreicher/inne/ $\mathrm{n}$ in Jerusalem, aufgenommen von den Teilnehmer/inne/n einer Exkursion der Salzburger Germanistik; zugänglich über das Deutsche Spracharchiv (wie Anm. 11), Korpus ISW. 
narrativen Interviews von ein bis drei Stunden Länge auf Band aufgenommen. Sie stammten v.a. aus Deutschland, Österreich und der Tschechoslowakei und wanderten größtenteils zwischen 1933 und 1940 in Erez Israel ein. ${ }^{13}$ Das Ziel war zunächst, ihr bildungsbürgerlich geprägtes Deutsch des ersten Drittels des 20. Jahrhunderts zu dokumentieren und die Gründe für die außergewöhnlich gute Sprachbewahrung herauszufinden, die angesichts der traumatischen Erfahrungen dieser Migrantengruppe - Vertreibung, Ermordung der Familie, Holocaust - alles andere als selbstverständlich erscheint. $^{14}$

Die ersten Publikationen zum Projekt waren daher diesen Fragen und der Analyse des an schriftsprachlichen Normen orientierten Deutsch der Sprecher gewidmet, die - obgleich ins so genannte „Land der Väter" gekommen - v.a. aufgrund des für die meisten sehr schwierigen Zugangs zur hebräischen Sprache nolens volens ihre Erstsprache Deutsch und die damit verbundenen kulturellen Ausdrucksformen in ihren z.T. sehr akademisch geprägten in-group-Zirkeln auf hohem Niveau weiter pflegten. ${ }^{15}$ Selbst manche Jugendliche partizipierten damals noch an dieser Sprachkultur und bauten ihre Ausdrucksfähigkeit im Deutschen auch ohne Schulunterricht noch weiter aus. ${ }^{16}$

In Betten/Du-nour (Hg.) (2000), ,Sprachbewahrung nach der Emigration" finden sich eine Reihe einschlägiger Beiträge: neben Analysen zu Syntax und Stil (Betten 2000a, b) va. die soziolinguistischen Untersuchungen von Miryam Du-nour zu den von den Immigranten hauptsächlich verwendeten Sprachen Deutsch, Englisch und Hebräisch aus der Perspektive des Erwerbs des Hebräischen und der allmählichen Verschiebung des Sprachengefüges (Du-nour 2000a). Aufschlussreich ist z.B. eine Tabelle, bei der nach Selbsteinschätzung der Interviewten das Alter zum Zeitpunkt der Immigration in Relation zur Beherrschung des Hebräischen im Sprechen, Lesen und Schreiben gebracht wird. Daraus geht hervor, dass alle, die bei der Einwanderung jünger als 15 Jahre waren, Hebräisch in allen drei Fähigkeiten perfekt beherrschen, während diese Vollkompetenz bereits bei den 15bis 18-Jährigen, die oft keine weiterführenden Schulen mehr besuchen konn-

13 Mit genaueren Angaben, u.a. zur Altersstruktur, siehe Du-nour (2000a) sowie die Einleitungen in Betten (Hg.) (1995) und Betten/Du-nour (2004).

${ }_{14}$ Vgl. auch Oppenrieder/Thurmair (2003, S. 55 f.) zur (meist temporären) „Sprachenabwahl“ v.a. bei Verfolgten des Naziregimes. Hierzu gehören auch die häufigen Fälle von Verweigerung der deutschen Sprache bei späteren Reisen nach Deutschland und Österreich (v.a. bei der ersten Rückkehr), vgl. die Beispiele aus dem Israel-Korpus in Betten (i.Dr.). Z.T. dauerhafte Folgen der Abwahl/Distanz vom Deutschen konstatierte Schmid (2002) bei jüdischen Emigranten in anglophonen Ländern, wo sich - im Gegensatz zu Israel - viel mehr Formen des Sprachabbaus finden ließen.

Vgl. dazu u.a. Betten (2000a, b).

16 Vgl. dazu Betten (2000b, S. 295 ff.), u.a. mit einem überaus komplexen Satzgefüge des mit 13 Jahren eingewanderten Abraham Frank, das ich wegen seiner kunstvollen Struktur (nicht aber Singularität!) auch in anderen Publikationen zitiert habe (z.B. in Betten 2011c, S. 68 f.). 
ten, um mehr als $40 \%$ zurückgeht, bei den 19- bis 24-Jährigen gar um über $70 \%$ (Du-nour 2000a, S. 201). Weitere Tabellen zeigen, dass in der Familie - wenn man die Verwendung von zwei Sprachen, Deutsch und Hebräisch, mit einbezieht $-75 \%$ mit dem Ehepartner und immerhin noch mehr als $50 \%$ mit den Kindern Deutsch bzw. auch Deutsch sprachen. ${ }^{17}$ Dies galt v.a. für das erste Kind und wurde oft bis zum Lebensende der Eltern beibehalten. Wegen der damaligen Tabuisierung des Deutschen glaubten übrigens die meisten, sie hätten zu den ganz wenigen Ausnahmen gehört. ${ }^{18}$

Interessant ist schließlich, dass rund 60 Jahre nach der Einwanderung nur 22\% Hebräisch in allen Gesprächssituationen verwenden und noch $20 \%$ am liebsten Deutsch sprechen. Beim Schreiben liegt das Hebräische bei diesen Durchschnittswerten weit hinter dem Deutschen. Besonders interessant ist in diesem speziellen Fall das Lesen: 33\% lesen fast kein Hebräisch und 74\% lesen bevorzugt Deutsch, daneben Englisch (darauf komme ich bei den Textbeispielen zurück): ${ }^{19}$

\begin{tabular}{|l|c|c|c|}
\hline & Sprechen & Lesen & Schreiben \\
\hline Deutsch & 20.0 & 23.1 & 34.6 \\
\hline Hebräisch & 21.9 & 5.6 & 12.2 \\
\hline Englisch & 0.6 & 8.8 & 3.2 \\
\hline $\begin{array}{l}\text { Deutsch und } \\
\text { Hebräisch }\end{array}$ & 28.1 & 11.9 & 16.0 \\
\hline $\begin{array}{l}\text { Englisch und } \\
\text { Hebräisch }\end{array}$ & 14.4 & 9.4 & 10.9 \\
\hline $\begin{array}{l}\text { Deutsch und } \\
\text { Englisch }\end{array}$ & 4.4 & 19.4 & 10.9 \\
\hline $\begin{array}{l}\text { Deutsch, Englisch } \\
\text { und Hebräisch }\end{array}$ & 10.0 & 19.4 & 0.6 \\
\hline andere & 0.6 & 2.4 & 11.5 \\
\hline
\end{tabular}

Im Folgenden werde ich hier jedoch weder grammatisch-stilistische Analysen des von den Emigranten teilweise selbst so genannten „Weimarer

17 Vgl. die Tabellen in Du-nour (2000a, S. 204, 206).

18 Vgl. dazu einen Kommentar von Dr. Hilde Rudberg in Betten/Du-nour (Hg:) (2000, S. 65 f.); im Zusammenhang mit dem Interview mit Rudbergs Tochter ferner Betten (2010, S. 52 f.).

Tabelle aus Du-nour (2000a, S. 208). 
Deutsch" ${ }^{20}$ noch strukturelle Analysen von Sprachkontaktphänomenen, Code-Switching und -Mixing ${ }^{21}$ vornehmen. Es geht vielmehr zentral um den Zusammenhang von Sprachverwendung und Identität.

Unsere Interviews sind weder klassische narrative autobiographische Interviews in dem Sinne, dass die Interviewten zunächst ungesteuert auswählen, was sie aus ihrem Leben erzählen, ${ }^{22}$ noch reine Sprachbiographien nach dem Motto „Wie bin ich zu meinen verschiedenen Sprachen gekommen? ${ }^{c 23}$ bzw. genereller ,Erleben und Umgang mit verschiedenen Sprachen im Verlauf des eigenen Lebens" (Franceschini 2010, S. 8). ${ }^{24}$ Sie weisen aber viele Gemeinsamkeiten mit beiden methodischen Zugängen auf ${ }^{25}$ und geben va. viel Material für Fragen nach kultureller und personaler Identität und deren Beziehung zu gesellschaftlichen/kollektiven Identitätsmustern.

Im Zentrum der folgenden Ausführungen steht daher der Zusammenhang von biographischen Brüchen und der Verdrängung der ursprünglichen Sozialisation einschließlich der daraus resultierenden weiteren „lebensgeschichtlichen Dynamik ${ }^{c c} .{ }^{26}$ Dies betrifft u.a. die Übernahme von Perspektiven, Identitätsmustern und -idealen der Aufnahmegesellschaft bei der kulturellen Neuorientierung und die damit verbundene neue Sprachenverteilung sowie die einzelsprachlichen Kompetenzen und Vorlieben. Dabei kommt der Art der Präsentation der Lebensgeschichte besondere Bedeutung zu, beginnend mit der Wahl der Textsorte(n) - Bericht, Erzählung, Argumentation, Anekdote etc. - bis zum Darstellungsmodus, z.B. ironisch-distanziert

20 Siehe den Textbeleg von Prof. Joseph Walk in Betten/Du-nour (Hg:) (2000, S. 143 f.); ausführlicher dazu Betten (2000a).

${ }^{21}$ Dazu Du-nour (2000b).

22 Siehe besonders Lucius-Hoene/Deppermann (2002, bes. S. 9 ff., 78 ff.). Vgl. ferner Rosenthal/Völter/Gilad (1999, S. 56) zur Offenheit der Erzählaufforderungen in ihren MehrGenerationen-Interviews in Israel seit 1992 auf der Basis der von Fritz Schütze initiierten Interview-Methode der interpretativen Sozialforschung. (Grundlegend dazu Rosenthal 1995, zu den Prinzipien der Gesprächsführung S. 186 ff.). Rosenthal arbeitete dabei mit dem (aus jeckischer Familie stammenden) israelischen Psychologen Bar-On zusammen; zu dessen eigener Methode siehe Bar-On (2004).

23 Überschrift des Vorworts von Franceschini/Miecznikowski (Hg.) (2004, S. VII).

${ }^{24}$ Von der ständig wachsenden Literatur zu Sprachbiographien und Sprachportraits seien als Bezugstexte noch genannt: Tophinke (2002), Treichel (2004), der es um die biographische Dimension von Mehrsprachigkeit geht (S. 21), sowie Busch (2010), die „nach dem Bezug des Spracherlebens zur individuellen Lebensgeschichte einerseits, zu historisch-gesellschaftlichen Konfigurationen mit ihren Zwängen, Machtgefügen, Diskursformationen und Sprachideologien andererseits" fragt (S. 58).

25 Zur Positionierung meiner Untersuchungen in der Forschung zu narrativen Interviews und in der Erzählforschung vgl. u.a. Betten (2007b, S. 105 ff., 2009, S. 227 ff.). Zu den Leitfragen für meine Interviews mit der 1. und 2. Generation und meinem methodischen Vorgehen siehe z.B. Betten (2010, S. 29-33, 2011b, S. 210 f.). - Eine Beschreibung des Interviewprojekts mit der 1. Emigrantengeneration in Hinblick auf die Sprachbiographie- und Oral History-Forschung findet sich bei Fix (2010, S. 13-16).

26 Dazu ausführlicher Rosenthal (2006, Zitat S. 234). 
oder emotional-reinszenierend. ${ }^{27}$ Diese sprachlichen und stilistischen Einzelelemente der Konstruktion der narrativen Identität sowie die von den Interviewten gewählten Strategien und sprachlichen Ausdrucksformen der Selbstund Fremdpositionierung sind gerade auch für die angestrebte Analyse, welche Auswirkungen das Migrationsschicksal auf Identitätsveränderungen und -rekonstruktionen hat, besonders aufschlussreich. Die Grundkonstellation des narrativen autobiographischen Interviews, dass das erzählende Ich zwischen den Zeitstufen seiner Biographie hin- und herwechseln kann, ermöglicht es, sowohl die Ausgangskonstellation und die Umbruchphase als auch weitere Stadien des Lebenslaufs in den Blick zu bekommen, inklusive vorläufiger Bilanzen und Evaluierungen aus der Perspektive der Erzählzeit ebenso wie aus der erzählten Zeit, aus Nähe und aus Distanz. ${ }^{28}$ Die Interviewten geben somit Einblick in gelungene und gescheiterte Lebensentwürfe und ermöglichen Eindrücke von ihrer Persönlichkeitsentwicklung. Die ausgewählten Textpassagen enthalten viele Formulierungshinweise auf diese Aspekte, deren sprachliche Detailanalyse aber hier nur gelegentlich möglich ist. Das Hauptaugenmerk wird vielmehr dem sprachlich-kulturellen Habitus gelten, der sich in diesen Selbstdarstellungen offenbart.

$\mathrm{Zu}$ den Interviews mit der 1. Generation werden ergänzend noch vier Interviews mit der 2. Generation herangezogen, da die Nachkommen der Einwanderergeneration ebenfalls noch von der Herkunftsidentität der Eltern und deren Umorientierungsproblemen betroffen und geprägt waren und sind. Als Kinder wurden sie besonders mit der Stigmatisierung dieser Identität als einer ,deutschen" konfrontiert und hatten sich spätestens dann mit den Identitätsangeboten des neuen gesellschaftlichen Kollektivs auseinanderzusetzen. ${ }^{29} \mathrm{Im}$ Gegensatz zu anderen Migrationen entstand bei ihnen allerdings kein Zwiespalt der Zugehörigkeitsgefühle zum Herkunftsland der Eltern oder dem eigenen Geburtsland Israel, das fraglos als Heimat betrachtet wurde, auch wenn es die familiale identitäre Prägung in Frage stellte; dies allerdings führte häufig zu Verunsicherungen bis zu psychischen Verstörungen. ${ }^{30}$

$27 \quad$ Vgl. dazu u.a. Betten (2009) und ausführlich Majer (2009).

${ }_{28}$ Dazu ausfühtlich Lucius-Hoene/Deppermann (2002, passim).

29 Detaillierter Betten (2010) und (2011a), Rosenthal (2006), Bar-On (2004, S. 14ff.).

30 Die Aufnahmen stammen aus einem Korpus von 62 Interviews mit der 2. Generation, die ich zwischen 1999 und 2007 in Israel geführt habe, ebenfalls zugänglich über das Deutsche Spracharchiv (siehe Anm. 11), Korpus ISZ. Die hier für die 2. Generation ausgewählten Beispiele betreffen nur Kinder, die bei ihren Eltern aufwuchsen und den Kontrast ihrer (jeckischen) Familienkultur zur Umgebungsgesellschaft zu verarbeiten hatten, was sie rückblickend oft als Überforderung durch das Leben in ; - Nochmals anders waren die psychischen Belastungen derer, die als Kinder ohne Eltern mit der so genannten Jugendalija eingewandert sind und zur 1. Generation gezählt werden (siehe Ada Brodsky). Zu deren Problemen und den ,transgenerationellen Folgen“ für ihre Nachkommen vgl. Rosenthal (2006), Urban (2006), Strutz (2006) sowie speziell zu Ada Brodsky Betten (ersch.demn.). - Zu „Loyalitätskonflikten mit den entsprechenden Brüchen, wenn 


\section{Die 1. Generation}

\subsection{Zur Auswahl der Fallstudien}

Aus der großen Bandbreite guter bis mangelhafter Integration der 1. Migrantengeneration, die in Kapitel 1 als Hintergrundinformation nur knapp angedeutet wurde, soll nun anhand einiger besonders erfolgreicher Beispiele von Einwanderern, die alle Hürden überwunden zu haben scheinen, gezeigt werden, wo selbst bei optimaler Verarbeitung einer Migration Verunsicherungen, Verlustgefühle, Bedauern oder auch Bitterkeit und Schmerz zurückbleiben. Dass auch bei dieser scheinbar vollständig integrierten Gruppe noch Spuren der ,kollektiven Schicksalsbetroffenheit ${ }^{631}$ der gesamten Migrationsgruppe festzustellen sind, gibt diesen ein besonderes Gewicht bzw. identifiziert sie als fast unüberwindbare Hindernisse. Aufschlussreich ist ferner, dass bei Lebensläufen, die auf den ersten Blick von den Ausgangsbedingungen und vom Resultat her vergleichbar erscheinen, doch ganz unterschiedliche Identitätsentwürfe gewählt wurden und sehr verschieden strukturierte neue Identitäten entstanden sind. ${ }^{32}$

Von den ausgewählten sechs Personen ${ }^{33}$ sind vier Professor/inn/en geworden: Paul Alsberg, Yehoshua Arieli, Joseph Walk, Leni Yahil. Ada Brodsky war bekannt als Musikredakteurin, Autorin von Künstlerbiographien und Übersetzerin. ${ }^{34}$ Als ,Durchschnittseinwanderin“ könnte am ehesten die Ehefrau von Prof. Alsberg, Betti, betrachtet werden: nicht weil sie

[...] zwei Gruppen, denen sich ein Individuum zugehörig fühlt, in Konkurrenz zueinander treten“" vgl. Oppenrieder/Thurmair (2003, S. 41): „Die nicht-dominante Sprache stört sozusagen die Loyalität gegenüber der dominanten Sprache, die ihrerseits zu den identitätsbildenden Konstanten der Großgruppe gehörtc (ebd., S. 47). Vgl. dazu aus meinen Interviews mit der 2. Generation Berichte wie die von Tom Lewy oder Michael Shilo, dass sie als Kinder auf der Straße viele Meter vor ihren Eltern gegangen seien, damit keiner merke, dass die zwei, die da Deutsch sprechen, zu ihnen gehören (siehe Betten 2010, S. 37; 2011b, S. 222).

31 So der Titel des klassischen Aufsatzes von Schütze (1982). Zur Forschungsgeschichte vgl. Straub (2004, S. 290 ff.).

32 Zur Entwicklung „pluraler ${ }^{c c}$ oder „multiple ${ }^{c c}$, komplexer Identitäten und Identitätsmodelle in der postmodernen Sozialpsychologie vgl. den Überblick bei Kresic (2006, S. 119 ff.): V.a. die von Heiner Keupp eingeführte „Patchworkmetapher" rücke ins Zentrum, dass es sich bei „der Konstruktion eines individuellen Identitätspatchworks [...] um einen lebenslangen, alltäglichen Prozess der Verknüpfung von Teilidentitäten" handle (ebd., S. 121). Vgl. dazu auch Lucius-Hoene/Deppermann (2002, S. 47 ff.), die aber auch (mit Jürgen Straub) „die Frage nach der Identität als Frage nach der Einheit der Person [...] im Hinblick auf Kontimuität und Kobären:s: (ebd., S. 48) betonen. Mit einem Überblick über Konzepte der personalen und der kollektiven Identität siehe Straub (2004).

33 Vgl. die Kurzbiographien aller hier behandelten Interviewpartner/innen im Anhang! Die Interviews mit Alsberg, Arieli, Brodsky und Yahil stehen auch im Zentrum von Schweiger (2011), die sich bei thren Identitätsanalysen v.a. auf pronominale Alternation und (sporadisch) Agency stützt. - Vollständige Transkripte der hier ausgewählten Interviews mit der 1. Generation finden sich unter den Zusatzmaterialien des Korpus IS im Deutschen Spracharchiv (siehe Anm. 11).

${ }^{34}$ Zu Brodsky ausführlich Betten (ersch.demn.). 
die Karriere ihrem Mann überließ, sondern aufgrund der Beschreibung ihrer mangelnden kulturellen Verwurzelung und eines gewissen Gefühls der Fremdheit im Alter. ${ }^{35}$ Typisch für die ganze Einwanderergeneration ist allerdings, dass auch die fünf sehr ,Erfolgreichen" nicht sofort bzw. auch nicht sofort nach dem Studium Karriere machten, sondern erst nach Unterbrechungen, die natürlich mit dem Zweiten Weltkrieg und seinen Folgen sowie dem Unabhängigkeitskrieg 1948 und der damaligen politisch und ökonomisch sehr prekären Situation des Landes zusammenhängen.

\subsection{Rückblicke auf Elternhaus, Kindheit und Jugend, Beginn der Umorientierung}

Da in den meisten Elternhäusern, ob völlig assimiliert oder traditionell und/ oder (gemäßigt) religiös orientiert, die deutsche Kultur einen hohen, wenn nicht alles andere übersteigenden Stellenwert besaß, ${ }^{36}$ ist es für die heutige Identitätsbestimmung der Emigranten aufschlussreich, in welcher Weise sie diese für sie später fragwürdige, erklärungsbedürftige, in der Aufnahmegesellschaft und vor sich selbst zu rechtfertigende Orientierung, die sie zunächst stark geprägt hat, aus heutiger Perspektive darstellen. Dies betrifft sowohl die Ausführlichkeit, mit der sie bereit sind, sich auf das Thema einzulassen, wie auch die Kommentierung bzw. Evaluierung. Hierzu drei unterschiedliche Beispiele.

Der Historiker Arieli, der aus Karlsbad stammt, legt großen Wert auf die Unterscheidung von deutscher Kultur und nationaler Zugehörigkeit sowie die Verbindung von Deutschem und Jüdischem in seinem Elternhaus. Seine zionistisch orientierte Familie emigrierte schon 1931, gehört also nicht zu den Zwangsemigranten. Dieser Umstand mag dazu beitragen, dass er sehr offen über die enge Bindung seiner Eltern an die deutsche Kultur spricht (vgl. Z. $31 \mathrm{ff}$, 50 ff.), die auch für seine eigene frühe kulturelle Prägung ausschlaggebend war (vgl. bes. Z. $46 \mathrm{ff} ., 55 \mathrm{f}$ ).: ${ }^{37}$

35 Vgl. Beispiel 8, Zeile 31-34 und Anmerkung 66.

36 Vgl. dazu kurz Betten (2000a, S. 174-180). Ausführlich hat Kremer (2007) die Bedeutung von deutscher Sprache und Bildung für das deutsche Judentum aus Quellen des 19. und 20. Jahrhunderts bis 1933 dokumentiert: Durch ebendiese Einstellungen wurden unsere Interviewpartner/innen in ihren Elternhäusern geprägt. Vgl. auch Braese (2010), der die deutsche Sprachkultur von Juden am Beispiel herausragender Persönlichkeiten behandelt.

37 Die Transkription sämtlicher Beispiele erfolgt nach GAT 2-,Basistranskript ${ }^{c c}$ (vgl. Selting et al. 2009). Wie im „Feintranskript" wurden neben Hauptakzenten auch Nebenakzente eingetragen. Aus Platzgründen wurde jedoch auf die Segmentierung in Intonationsphrasen sowie auf den Eintrag von Hörersignalen, die den Verlauf des Dialogs nicht offensichtlich beeinflussen, verzichtet. Ich danke Michaela Metz für ihre umfangreiche Hilfe beim Transkribieren und Formatieren (auch der vielen zusätzlichen Beispiele im Handout zum mündlichen Vortrag) und Simona Leonardi für wertvolle Hinweise! - Mit längeren Ausführungen Arielis zu seiner hier nur angedeuteten Theorie von der „deutschen Reinkultur ${ }^{c t}$ der tschechischen und mährischen Juden vgl. den Textausschnitt in Betten/Du-nour (2004, S. 281 f.). 
Beispiel 1: Yehoshua Arieli [5min 34s - 8min 11s]

$01 \mathrm{MD}$ : also kArlsbad war doch ei (--) eigentlich eine

02

03

04

05

06

07

08

09

10

11

12

13

deutsch: (--) DEUTsche stadt. ${ }^{\circ}$ hhh äh: : (--) also hast (--) hast du (-) konTAKT gehabt; (.) mit den suDEtendeutschen. (--) die: dort geLEBT haben. (-) hast du dich gefÜhlt (-) ein bisschen mit der kulTuR: wenigstens. ${ }^{\circ}$ hh ein suDEtendeutscher? (-)

YA: NEIN. 'hhh äh: SCHAU. äh: :_äh wir ha_ich hab VIEL, ich hab (--) den normAlen konTAKT das jedes kind hAt. ${ }^{\circ}$ hh mit seiner umGEbung, ich bin doch in die sCHUle gegangen; neun JAHre, ${ }^{\circ}$ hhh und wir haben NACHbArn gehabt, so dass sozusagen ${ }^{\circ}$ hh äh: : äh wi_äh d_m:: mein LEben, äh äh:; spielte sich (-) im sudeten (--) DEUTschen kreis $A b$, mit sehr $v$ :_starkem jüdischen EINschlag, ${ }^{\circ} \mathrm{hh}$ : und äh:_i viele meiner jüd_kind äh_k_äh: frEUndsch_äh: freunde oder ${ }^{\circ} \mathrm{h}$ be (.) jedenfalls bekAnnten in der schule waren $\mathrm{ja}$ alle ${ }^{\circ} \mathrm{h}$ nIchtjüdische ${ }^{\circ} \mathrm{h}$ äh nichtjüdische äh:_k_äh: suDEtenkinder,_v äh von denen einige ${ }^{\circ} \mathrm{hh}$ sozusagen auf_m LAND (-) wachsen, und noch diesen (-) sudEtendialekt geSPROchen ham; ${ }^{\circ} \mathrm{h}$ den ich ja kaum KANnte. ${ }^{\circ}$ hhh äh:_j aber ich KANN nicht sagen; dass ich irgendwie ein: ein ein geFÜHL hatte; ${ }^{\circ} \mathrm{h}$ ein suDEtenpatriot zu sEIn, ${ }^{\circ} \mathrm{hh}$ obwohl natürlich die ${ }^{\circ} \mathrm{h}$ umGEbung von kArlsbad; äh HERRlich ist, ${ }^{\circ} \mathrm{h}$ und wir VIEL; (klopft auf den tisch)) meine_f (ga)_auch meine familie und auch ich VIEL viel ${ }^{\circ} \mathrm{hh}$ äh: herUmgewandert sind. ${ }^{\circ} \mathrm{h}$ !A!ber. ${ }^{\circ} \mathrm{h}$ unsere kulTUR; (--) äh: und jetzt sag ich ! UN!sere kultur war natürlich ${ }^{\circ} \mathrm{h}$ die klassische deutsche kultur. ${ }^{\circ}$ hh und: nicht die suDEtenkultur, weil es ja so was kaum GAB, oder <<lachend> jedenfalls> ich (xxx xxx) (.) bin ${ }^{\circ} \mathrm{h}$ mich dessen nicht bewusst, ${ }^{\circ} \mathrm{hh}$ aber wie Alle (.) $j$ (.) deutschsprechigen $j$ Uden in der in böhmen und_und in der ${ }^{\circ} \mathrm{h}$ in äh in der (.) in MÄHren, ${ }^{\circ}$ hh ihre HEIMkultur; ihre RICHtige kultur war die kultUr; ${ }^{\circ} \mathrm{h}$ entweder von WIEN oder prAg, (-) oder (-) DEUTSCHland, (-) die 
sozusagen ${ }^{\circ} \mathrm{h}$ das gEIstig humanistisch DEUTsche kultur, (-) euroPÄischdeutsche kultur dArgestellt hat ${ }^{\circ} h$ äh wie: die juden sie eben; (-) sowohl entwICkelt haben wie auch akzeptiert haben. ${ }^{\circ} \mathrm{hh}$ sodass ich als kind ${ }^{\circ} \mathrm{h}$ !VOLI! kommen in der deutschen kultur AUfgewachsen bin, ${ }^{\circ}$ hh vom theAter und von ELtern, ${ }^{\circ} \mathrm{h}$ die s_ungeheurer verwAchsen waren mit ${ }^{\circ} \mathrm{h}$ mit der: also mit der deutschen kulTuR; und der ${ }^{\circ} \mathrm{h}$ dIchtung und der philosophIE und äh und der KUNST, ${ }^{\circ}$ hh so (.) dass in (.) DIEsen sinn; ${ }^{\circ} \mathrm{h}$ äh war mein (-) war m: : mein MUTterkultur wirklich äh: die deutsche kultur,

Ganz anders spricht dagegen über diesen Teil ihrer Vergangenheit die Historikerin Leni Yahil, die in Berlin aufwuchs. Sie erwähnt z.B. nicht (bzw. nie), dass ein Teil ihrer Familie zur katholisch gewordenen Linie der Moses-Mendelssohn-Nachkommen gehörte, ${ }^{38}$ und geht über die völlig deutsche Prägung ihrer Jugendzeit soz. ex negativo, aus jüdischer Perspektive, hinweg (nicht sehr jüdisch bestimmt, Z. 2f.). Umso mehr hebt sie stattdessen ihre persönliche Hinwendung zum Jüdischen seit Ende der 1920er Jahre hervor (Z. $20 \mathrm{ff}$.), da ihr dies für ihre spätere identitäre Ausrichtung sehr wichtig ist:

Beispiel 2: Leni Yahil [1min 48s - 2min 59s]

01 LY: ((..)) ich bin AUFgewachsen äh: : in einer:

02 (.) umgEbung; äh die die: :_äh nIcht sehr:

03 jüdisch besTIMMT war, ${ }^{\circ}$ hhh und äh: : und auf

04 der ANderen seite; (-) äh äh der: dass da ( $\mathrm{xxx} \mathrm{xxx}$ ) ALLgemein; es war in der nähe von berLIN, ${ }^{\circ}$ hh und die allgemeIne: : stimmung äh: ${ }^{\circ} \mathrm{h}$ war sehr geTEILT. ${ }^{\circ} \mathrm{h}$ äh äh $(\mathrm{xxx} \mathrm{xxx})$ die: hatten eine:_äh: unsere klAssenlehrerin war soziALdemokratin, ${ }^{\circ}$ hh und in der KLASse waren_äh:; auch schülerinnen die: (.) die nachher: äh gute NAzis geworden sind. also das war sehr ${ }^{\circ}$ hh äh geMISCHT. die die ganze:

38 Recherchiert von Schweiger (2011, S. 287) mit Literaturangaben. Vgl. auch Anmerkung 50. 
atmosPHÄre. ((räuspert sich)) äh: (-) mich hat

äh: : (-) vor: von vornhereIN schon. von (-)

FRÜH an; hat mich äh: geschIchte sehr interesSIERT, ${ }^{\circ}$ hh geschichte und ((räuspert sich)) auch literaTUR, (--) ${ }^{\circ} \mathrm{h}$ und das hab ich nachher Angefangen in deutschland zu stuDIEren, aber nicht (-) sehr LANge, aber $z u$ (-) inzwIschen bin ich (aber auch) hiNEINgekommen; ${ }^{\circ} \mathrm{hh}$ in_die krEIse der: jüdischen JUgendbewegung, ${ }^{\circ}$ hh und hab mich dann sehr: viel mit äh:: mit den Jüdischen problemen befasst, und_äh: heBRÄisch angefangen zu lernen, ( (..))

Paul Alsberg hingegen, der auch Historiker wurde, berichtet vor dem hier präsentierten Textausschnitt sehr offen und ausführlich, wie assimiliert und unjüdisch sein Elternhaus war, bis er sich unter dem Druck der Erfahrungen der Nazizeit in Hinblick auf seine Auswanderung jüdische Kenntnisse in einem Rabbinerseminar zu verschaffen suchte: ${ }^{39}$

\section{Beispiel 3: Paul Avraham Alsberg [20min 45s - 21min 31s]}

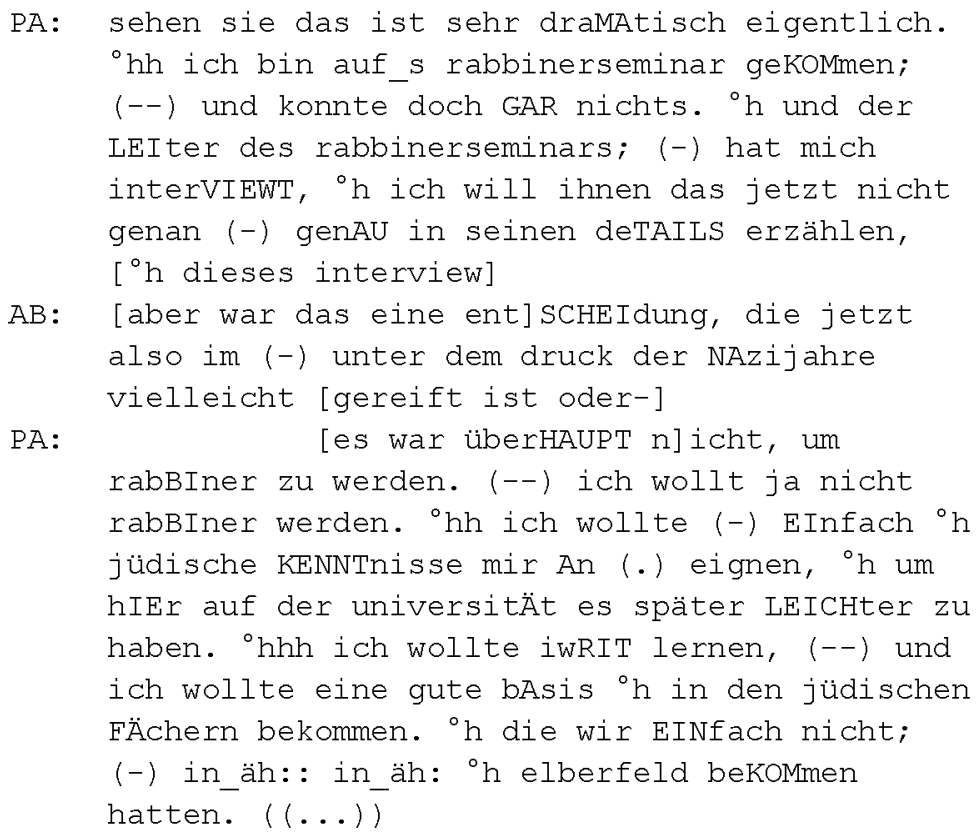

Für einen längeren Ausschnitt dieser Stelle siehe Betten/Du-nour (2004, S. 21). 
2.3 Die sprachliche und kulturelle Umstellung:

Probleme, Konflikte

Leni Yahil und Paul Alsberg waren bei der Emigration junge Studenten, die in Jerusalem bald weiterstudierten. Aber während Yahil betont, wie bewusst sie den Übergang in die hebräische Sprache betrieben hat, indem sie sich z.B. von Anfang an alle Notizen auf Hebräisch zu machen versuchte, ${ }^{40} \mathrm{er}-$ zählt Alsberg genüsslich eine Anekdote, wie er, als er Texte ins Hebräische übersetzen sollte, zunächst einmal durchfiel. ${ }^{41}$

Yehoshua Arieli und Ada Brodsky waren erst 15 bzw. knapp 14 Jahre alt, als sie ins Land kamen. Beide lebten von da an getrennt von ihren Eltern. Sie kamen beide - allerdings zu unterschiedlichen Zeiten - zunächst auf die berühmte Landwirtschaftsschule Ben Shemen. ${ }^{22}$ Die Jugendlichen wurden dort in Hebräisch, jüdischem Wissen und Landwirtschaft unterwiesen. ${ }^{43}$ Brodsky, die als junges Mädchen in Deutschland schon Preise für eigene kleine Prosatexte bekommen hatte, ${ }^{44}$ beschreibt anschaulich, ebenso berührend wie für die Migrationslinguistik aufschlussreich, dass sie dort zwar rasch zu sprechen lernte, sich aber mit dem selbstständigen Schreiben - zunächst mit Aufsätzen und später mit dem schöpferischen Schreiben - schwer tat, was sie bis zuletzt mit Bitterkeit erfüllte. Mangelhafte Kenntnisse der Bibelsprache, aber auch des neuen Milieus hinderten sie daran:

Hier hatte ich das Gefïhl, dass mir alles aus den Händen/ dass ich selbst nirgendwo richtig qu irgendeinem Kreis gehöre [...] was ich bin, ist überhaupt nicht etwas, worum man in diesem Land schreibt. Man muss schreiben über Chaluqim, über Pioniere, über alles Mögliche, das mir nicht gehört, wohin ich nicht gehöre. ${ }^{45}$

40 Vgl. den Textausschnitt in Betten/Du-nour (2004, S. 317 f.).

${ }^{41}$ Vgl. ausführlich in Betten/Du-nour (2004, S. 315).

42 Das Jugenddorf Ben Shemen wurde 1927 von dem aus Deutschland stammenden Arzt und Reformpädagogen Siegfried Lehmann gegründet. Anstelle von Hinweisen auf die zahlreiche Literatur darüber ein Auszug aus Arielis Beschreibung: „Der Leiter dieser Schule, der ein ganz besonderer Mann war, Dr. Lehmann, hat dort die Erziehungsideale der deutschen Jugendschulen eingeführt"; vom Gedanklichen wie auch vom Künstlerischen her sei „irgendwie die deutsche Kultur da nach Ben Schemen mitgewandert" und habe sich „dort sozusagen transformiert [...] ins Hebräische, aber als richtiges Kulturereignis" (aus Betten/Du-nour 2004, S. 291). Dies kam natürlich besonders den Kindern entgegen, die wie Ada Brodsky im Rahmen der Jugendalija (siehe Anm. 30) aus Hitler-Deutschland dort Aufnahme fanden.

43 Zu den damit verbundenen Erzichungsidealen des „neuen Israeli “c bzw. Pioniers siehe u.a. Rosenthal (2006), Śegev (2008, v.a. Kap. 5).

44 Vgl. ihre eigene Kindheitsbeschreibung in Brodsky/Neumark (2000) sowie Jessen (2011) auf der Basis eines Interviews mit Ada Brodsky im Jahr 2007.

45 Wesentlich ausführlicher ist diese aufschlussreiche Stelle in Betten/Du-nour (2004, S. 333335) wiedergegeben: dort leicht ,gegtättet“, hier im Originalwortlaut des Transkripts. 
Die Verunsicherung drückt sich heute noch in einer hier (und im weiteren Kontext) auffalligen Formulierungsunsicherheit der sonst so Wortgewandten aus.

Von Problemen anderer Art, mit denen fast alle Neueinwanderer aus Deutschland konfrontiert waren, berichtet Pädagogikprofessor Joseph Walk. Er war nach der Einwanderung bereits Erzieher für die mit der Jugendalija ins Land gekommenen Jugendlichen ${ }^{46}$ und Lehrer im Dorf, wo er und seine Familie von der Mehrheit der aus Osteuropa stammenden Arbeiter nicht besonders freundlich behandelt wurden: ${ }^{47}$

\section{Beispiel 4: Joseph Walk [30min 51s - 32min 44s]}

$01 \mathrm{JW}:((\ldots))$ ich kam

02 neunzehnhundertse_sechsunddreißig ins LAND, inzwischen war ich LEHrer, ${ }^{\circ} \mathrm{h}(-)$ äh war jugendalija (--) äh lEIter hier im LANde, ${ }^{\circ} \mathrm{h}$ und kam dann:_äh: Als jugendalijaführer in ein (-) DORF, wo etwa nur fünfundzwanzig prozent JECKes waren, ${ }^{\circ} h$ alle ander_n stammten aus Polen; LItauen; UNgarn, ${ }^{\circ} \mathrm{h}$ und waren nicht g_rade sehr jeckenfreundlich EINgestellt. ${ }^{\circ} \mathrm{hh}$ und nun geschah FoLgendes. (1.5) im jahre (.) etwa neunzehnhundertzweiundVIERzig; als doch schon DURCHgesickert war, (--) LANGsam; ${ }^{\circ} \mathrm{h}$ was eigentlich pasSIERT? (--) erschien in der: parTEIzeitung, der: (-) damaligen (-) religiösen ARbeiterschaft, die auch HEUte noch erscheint- ${ }^{\circ}$ hh ein artikel zuNÄCHST (-) gegen die deutsche kulTuR, (---) und die: Endeten alle mit angriffen auf uns JECkes. (---) als wenn wir nun: (.) äh (.) ich würde SAgen; ${ }^{\circ} \mathrm{h}$ der nächstLIEgende; (--) GREIFbare gEgner wären. ${ }^{\circ}$ hhh das hat uns emPÖRT, und ich hab damals als leiter der kulturkommission dieses ortes; (-) ich war LEHrer dort, ${ }^{\circ} \mathrm{h}$ habe ich äh: eine gesprochene zeItung herausgegeben, und ein: (--) auch aus DEUTSCHland stammender; (--) äh: : (--) chaVER, (-) das kann man schwer übersETzen. ${ }^{\circ} \mathrm{h}$ mitbewohner, geNosse, ${ }^{\circ} \mathrm{hhh}$ der kam ZU mIr_und_sagte, hör mal zU, ich will einen LEITartikel schreiben; in der nächsten

Vgl. Anmerkungen 30 und 42.

Zum Verhältnis Jeckes - Ostjuden vgl. nochmals Anmerkungen 1 und 8. 


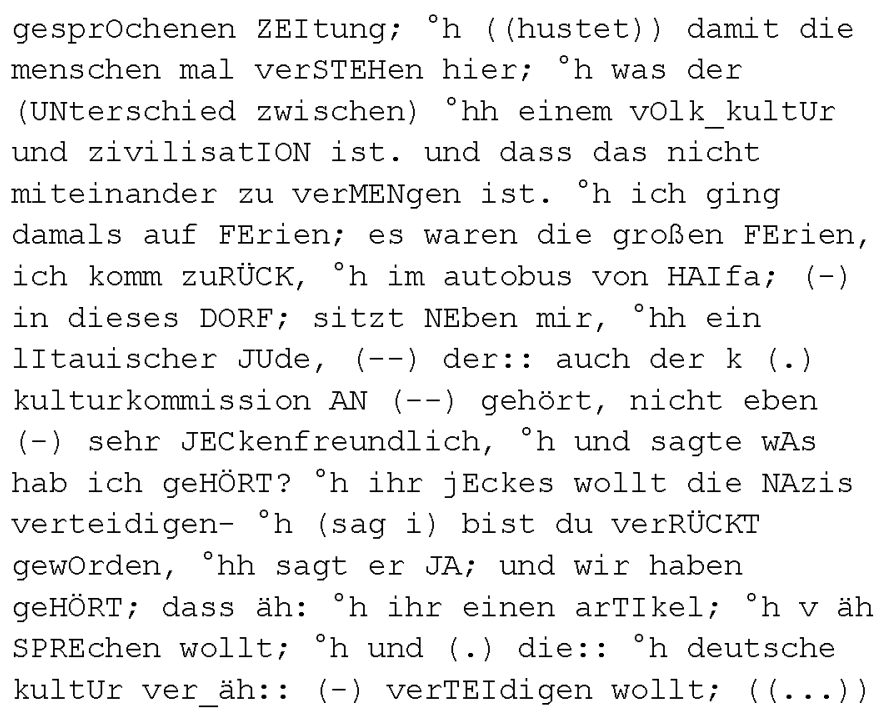

Walk und viele andere Jeckes haben diese konfrontative Ablehnung ihrer kulturellen Identität (vgl. Z. $16 \mathrm{ff}$., $45 \mathrm{f}$.), die bis zur Unterstellung einer Nähe zu den Nazis ging (Z. 41 f.), nie vergessen, auch wenn ihre Einstellung zum israelischen Kollektiv sich im Laufe der Jahre geändert hat. Walk positioniert sich mit diesen, aber auch anderen Einstellungen (z.B. seinen politischenn) ${ }^{48}$ eindeutig in der Gruppe der Jeckes (vgl. Z. 18, 40 f.), während er in anderer Hinsicht (so in seiner religiösen Ausrichtung und der damit einhergehenden tiefen Verbindung mit der hebräischen Sprache, siehe 2.4) von den typisch jeckischen Identitätsmerkmalen abweicht. Dass ,eine kollektive Identität [...] Mehrfachzugehörigkeiten einer Person zu verschiedenen Gruppen" keineswegs ausschließt (Straub 2004, S. 300), werden auch die folgenden Beispiele untermauern.

2.4 Der Aus- und Umbau der Identität in späteren Lebensstadien; Lebensbilanzen

Besonders relevant für das Thema des Identitätsumbaus ist auch der Rückblick der Interviewten auf spätere Stadien ihres Lebens, in denen sie nach den ersten Bemühungen um Integration ihre Identitätsentwürfe mehr oder weniger selbstbestimmt in neue, für ihr weiteres Leben entscheidende Richtungen lenkten.

48 Vgl. seine Ausführungen zur humanistischen Tradition der deutschen Juden, die sich bereits in dem 1926 gegründeten ,Friedensbund ${ }^{`}$ Brit Schalom für einen binationalen Staat Palästina einsetzten, und zu seinen eigenen Aktivitäten in der religiösen Friedensbewegung: Textausschnitte in Betten (Hg.) (1995, S 409-411). Aus entgegengesetzter Haltung ist dies auch ein zentrales Thema im Interview mit seiner Tochter Shulamit, siehe unten Beispiel 12. 
Ada Brodsky hatte sich durch ihren Wunsch, ein Gymnasium zu besuchen und das Abitur zu machen, zwar schon von dem für sie vorgesehenen „Pionierweg" der Landwirtschaftsschule abgewandt, aber mit ihrem ersten Studienfach Judaismus doch auf andere Weise versucht, die Erwartungen, die in eine Einwanderin gesetzt wurden, zu erfüllen. ${ }^{49} \mathrm{Nach}$ einigen biographischen Intermezzi - wie Heirat, Kind, Betreuung von Lagerüberlebenden in Zypern - brach sie dieses Studium jedoch ab und verwirklichte nach dem Tod ihres Vaters, der das Musikstudium nur für ihren begabteren Bruder vorgesehen hatte, nun selbstbewusst geworden, ihren Traum. Das folgende Textbeispiel offenbart ironische Distanz zu dem Anpassungszwang unter die herrschende Ideologie, dem sie sich zunächst unterworfen hatte, aber auch zu ihrer damaligen neuen Selbstsicherheit; es enthält alle Ingredienzien der Reflexion über Identitätszwänge und dazu im Widerspruch stehende geheime Wünsche:

\section{Beispiel 5: Ada Brodsky [36min 48s - 37min 42s]}

$A B: \quad((\ldots))$ dann hAb ich mir geDACHT; also JETZT (-) kann ich machen; was ich WILL- ${ }^{\circ}$ hhh (---) und jetzt_sch (-) pfeIfe ich auf den judaIsmus. ich: (-) das äh: das WAR sOzusagen auch äh:; (-) ${ }^{\circ} \mathrm{h}$ dAs was man eben äh: was man eben dem land SCHULdig ist. NICHT, s:ich für seine kultur zu interesSIEren; ich hab geSAGT, also JETZT, (.) ich hab schon: WEISS ich; äh was ich schon alles geMACHT hab auf dieser welt- jetzt war ich in zYpern; und hab dort ${ }^{\circ}$ hhh HELdentaten vollbracht. und jetzt hab ich schon ein KIND überhaupt diesem lAnde geschenkt; also jetzt mache ich einfach ${ }^{\circ} \mathrm{hh}$ NICHT das; was ich am BESten kAnn, sondern das was ich am be (.) am MEISten wIll. (1.5) und das war musik. (---) ${ }^{\circ}$ hh und da ließ ich alles stehen und LIEgen; und ging (and die) muSIK(ens). äh: akadeMIE und hatte so: : ; (.) f: (.) äh war wie so ähm ein TRAUM. denn das hätt (ich) mir nIEmals voRgestellt; dass Ich in meinem leben musIK studIEre- weil ich doch GAR nicht so schrecklich begAbt war oder so${ }^{\circ}$ hh nur dass ich das eben g_rade schrEcklich schrecklich LIEBte. ( (..))

49 Vgl. Rosenthal (2006, S. 235 ff.) und Hansen-Schaberg (2006, S. 189 ff.) über den Druck zur Integration und Akkulturation, der besonders auf den als Kinder und Jugendliche Immigrierten lastete. 
In unserem Zusammenhang wichtig ist jedoch va., dass es Brodsky durch diese Entscheidung möglich wurde, in ihrem weiteren Leben ihren israelischen Hörern und Lesern die deutsch-europäischen Meisterwerke der Musik und Literatur auf Hebräisch nahezubringen. Damit hatte sie eine Legitimation gefunden, sich wieder mit deutscher Kultur und Sprache zu beschäftigen und konnte somit für sich selbst eine Brücke schlagen zwischen ihrer einst so geliebten Herkunftskultur und der neuen Lebenswelt - was ihr Publikum, das ähnliche Erfahrungen verarbeiten musste, ihr mit großer Dankbarkeit lohnte.

Bei Leni Yahil hingegen, deren Großvater mütterlicherseits, James Simon, einst Kunstmäzen des deutschen Kaisers war, ${ }^{50}$ sitzt die Verletzung zu tief, um überhaupt angesprochen werden zu dürfen. Sie wandte sich konsequent von der Beschäftigung mit deutscher Kultur ab. Ihr wissenschaftliches Lebensthema wurde die deutsche Unkultur - der Holocaust. In den ersten Jahren nach dem Studium engagierte sich die großbürgerlich Aufgewachsene besonders in der Arbeiterbewegung, was sie als einen in vieler Hinsicht entscheidenden Wendepunkt in ibrem Leben bezeichnet (Bsp. 6, Z. 3 f.). Sie suchte damit die volle Identifikation mit den damaligen ideologischen Positionen und Idealen des jungen jüdischen Staates - und diese Ausrichtung hat sie bis zuletzt beibehalten. Ihre journalistische Tätigkeit, z.B. für die Zeitung der Arbeiterbewegung (siehe Z. 14ff.), hatte nichts mehr mit ihrer Herkunftskultur gemein; der Hinweis darauf dient eher der Bestätigung ihrer nun ganz anderen Identitätsbestimmung:

\section{Beispiel 6: Leni Yahil [29min $8 \mathrm{~s}-29 \mathrm{~min} 57 \mathrm{~s}$ ]}

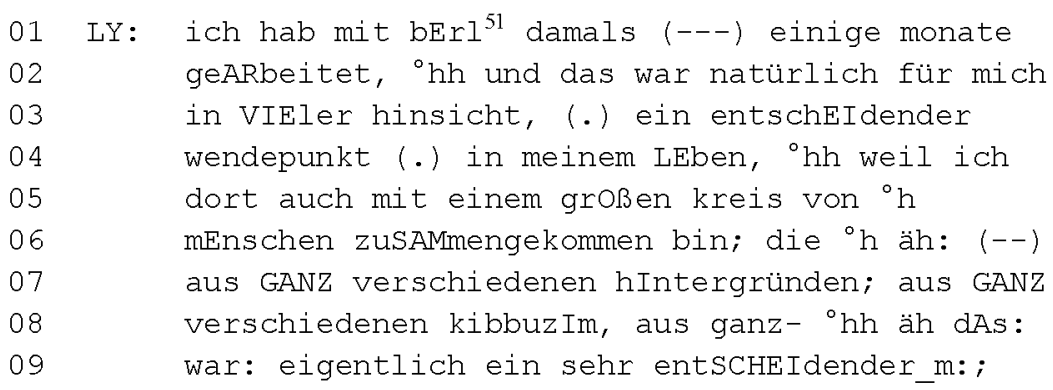

50 Vgl. ausführlich Matthes (2000); dieses Buch hat mir Leni Yahil zugeschickt, die einmal anmerkte, wenn sie das Interview mit mir (und nicht ihrer israelischen Freundin aus denselben politisch-zionistischen Kreisen) gemacht hätte, wäre es sicher ganz anders ausgefallen: $\mathrm{Ob}$ sie damit andeuten wollte, dass sie dann mehr über die Rolle ihrer Familie in Deutschland und ihre diesbezüglichen Gefühle preisgegeben hätte, blieb ungeklärt.

51 Berl Katznelson (1887-1944): bedeutender israelischer Arbeiterführer, Journalist, Politiker; Vertrauter Ben Gurions, in den 1920er Jahren Mitbegründer zionistisch-sozialistischer Parteien und Institutionen, 1925 Gründer der ersten Zeitung der Arbeiterbewegung Dawar, seit 1939 Initiator der illegalen Einwanderung für Flüchtlinge aus Europa, etc. 

entwICKlung, ${ }^{\circ} \mathrm{hh}$ und ich bin dann danAch in tel aVIV geblieben, und hab dann: äh: (.) wie gesagt auch (-) sowohl in der: (-) in der: Arbeiterinnenbewegung ${ }^{\circ} \mathrm{hh}$ geARbeitet, ich hab dann auch später: äh (-) das: (-) das orGAN, was: die (.) ver (.) die:

17 MD: dwar hapoelet.=

18 LY: =die dwar hapoElet mit äh redigIERT, und mit heRAUSgebracht und ${ }^{\circ}$ hh hab auch im daWAR in:_d äh später geArbeitet, ( (..))

Viel unangestrengter hinsichtlich seiner ideologischen Ausrichtungen und auch Schwankungen gibt sich dagegen, zumindest im Rückblick, Yehoshua Arieli $^{52}$ - vielleicht weil er, schon aus einer zionistischen Familie kommend, den Zionismus nicht für sich erkämpfen und seine Glaubwürdigkeit nicht beweisen musste, was für die Jeckes hingegen eine ständige Herausforderung blieb: „Kommst du aus Überzeugung oder kommst du aus Deutschland?" mussten sich die Hitler-Flüchtlinge oft fragen lassen. Arieli hingegen berichtet ganz locker, dass er durch die Heirat mit einer Sabre in eine vollkommen israelitische Gesellschaft hineingekommen sei ( $Z$. $5 \mathrm{ff}$.), wodurch das deutsche Element ... als bildendes Kulturerlebnis vollkommen verblasst sei (Z. 13-19):. ${ }^{53}$

\section{Beispiel 7: Yehoshua Arieli [80min 15s - 82min 59s]}

01 YA: ((..)) inzwischen hab ich mich (--) mit äh: :

02 (-) verHEIratet, neunzehnhundertv: (-) äh: (.)

03 SIE_Mundvierzig, mit der yael

04 [Auslassung: 17s]

05 YA: die eine SAbre ist, ${ }^{\circ}$ hh und bin DAdurch; (.)

06 also schon (--) nicht nur wegen $(--)$ aus an ANder_n gründen; ${ }^{\circ} \mathrm{hh}$ in eine vollkommen (-) äh äh: israelitische gesellschaft heREINge; (.) WAS ja auch mit der; ${ }^{\circ}$ hh äh: heREINgekommen. was ja auch äh d (-) war naTÜRlich; ${ }^{\circ} \mathrm{h}$ mit allen ANder_n erlEbnissen;

$52 \quad$ Arielis Selbstdarstellung lässt sich, nach Straub (2004, S. 290 unter Bezug auf Honneths „Kriterien einer dezentrierten Autonomie “) eher als autonomer Verzicht interpretieren, „das eigene Leben einem 'einzigen Sinnbezug' unterzuordnen, sondern es vielmehr im Zuge einer narrativen Synthese des Heterogenen " zu repräsentieren und zu reflektieren.

53 Mit einer anderen Stelle, an der Arieli seine istaelische Kultur ,der Pionierzeit und des Lebens" mit dem vergleicht, was er unter einer wirklich „hebräischen Kultur" versteht, siehe Betten/Du-nour (2004, S. 293 f.). 
die ich zuvor und so weiter HATte, ${ }^{\circ}$ hhh (-) so dass im GRUNde genommen, was du N::ENnen könntest, ${ }^{\circ} \mathrm{hh}$ das deutsche: (-) element (-) ${ }^{\circ} \mathrm{h}$ äh va (.) vollkommen verBLASST ist. äh: äh: äh: in ${ }^{\circ} \mathrm{hh}$ äh: : (-) als jedenfalls als ${ }^{\circ} \mathrm{h}(-)$ bildendes äh: kulturerLEBnis. äh vollkommen neunzehnVIERundfünfzig, ${ }^{\circ}$ hh waren für mich von JE:dem standpunkt her getroffen- (-) UNgeheuer wIchtig. auch vom kultuRELlen her. ${ }^{\circ}$ hh ERStens hab ich; ${ }^{\circ} \mathrm{h}$ hab ich amerika akzeptiert als ${ }^{\circ} \mathrm{h}$ als (.) kuk eine kulTUR; oder als eine geSELLschaft; ${ }^{\circ}$ hh die in VIElem für mich äh: (.) äh: nicht nur hochinteresSANT sondern; ${ }^{\circ} \mathrm{hh}$ ein GANZ neuer typus einer kultur; einer geSELLschaft war, ${ }^{\circ} \mathrm{h}$ und in VIElem; habe ich sie hochgesCHÄTzT, $((\ldots))$

Mit allen anderen Enlebnissen, die ich zuvor ... hatte (siehe Z. 12 f.) sind v.a. vier Jahre in deutscher Kriegsgefangenschaft als Offizier der britischen Armee von 1941-45 gemeint, in denen er, unter ständiger Lebensgefahr, Deutsch und Deutsche von der übelsten Seite kennenlernte. ${ }^{54}$ Besonders abgestoßen hat ihn, wie er an anderer Stelle des Interviews ausführt, ihr vollkommen primitives, schreiendes Soldatendeutsch. Seitdem ist ihm Deutsch als öffentliche Kunstsprache (z.B. auf dem Theater) unerträglich: weil ich es ibnen nicht mehr glaube. ${ }^{55}$

54 Siehe dazu die Textausschnitte in Betten (Hg.) (1995, S. 239 f.) und Betten/Du-nour (2004, S. 216).

55 Vgt. den Textausschnitt in Betten/Du-nour (2004, S. 306 f.). Der auf das obige Zitat unmittelbar folgende Satz lautet: Das ist ein Vorurteil natürtich. Als analytisch denkender Wissenschaftler ist Arieli der Zusammenhang zwischen Klangempfinden, Spracheinstellung, Stereotyp und Vorurteil bewusst (vgl. etwa die Definition von Spracheinstellungen „als Bündel von kognitiv, affektiv-evaluativ sowie prä- und proskriptiv ausgerichteten Meinungen über Sprache, Sprachverwendung und die Benutzer von Sprache zugleich" von Portz 1982, S. 93). Die affektive Einstellung bzw. konnotative Verknüpfung der deutschen Sprache mit den schrecklichen persönlichen (bei den nachfolgenden Generationen nur medial vermittelten) Erfahrungen mit ihren Sprechern bleibt für den Privatmenschen jedoch ausschlaggebend und unauslöschbar. Ausgehend von Ansätzen von Bourdieu, Bachtin, Kristeva, Kramsch gibt Busch (2010, S. 60 f.) interessante Hinweise, wie die „subjektive[.] Wahrnehmung bestimmter symbolischer (sprachlicher) Formen“ - z.B. die „Art, wie ein Klang empfunden und interpretiert wird" - mit „Entwürfe[n] von Subjektpositionen verknüpft" ist. - (Ganz unterschiedliche) Assoziationen zum Klang des Deutschen äußern in meinen Interviews 
- Wenn für Arieli selbst ein 21/2-jähriges Harvard-Stipendium von jedem Standpunkt her ... ungeheuer wichtig wurde, auch vom Kulturellen ber (siehe Z. 25 ff.), so war es für ihn später als Professor für Amerikanische Geschichte in Jerusalem aufgrund dieser Erfahrungen mit einer anderen Kultur und Gesellschaft ein Hauptanliegen, seinen israelischen Studenten Kenntnis und Wertschätzung anderer Kulturen als (nur) der jüdischen und das Bewusstsein einer allgemeinen Menschlichkeit zu vermitteln. ${ }^{56}$

Für die mit ihm befreundete Interviewerin Du-nour äußerst überraschend war allerdings, dass Arieli, der für viele die Musterbiographie der Pionierzeit und zugleich eines erfolgreichen israelischen Wissenschaftlers verkörperte, seine Beziehung zur hebräischen Kultur selbstkritisch als eine im Grunde genommen oberflächliche bezeichnete, die bei ihm nie ein Konkurrent fïr das Deutsch-Europäische und später Englische geworden sei. ${ }^{57}$ Auch seine Hauptsprachen beim Lesen sind Englisch und Deutsch. ${ }^{58}$

Joseph Walk erläutert sehr detailliert, wie es in seinen drei Sprachen um die einzelnen Kompetenzen bestellt ist. Im Gegensatz zu den allermeisten seiner Altersgruppe hält er seine schriftliche Ausdruckfähigkeit im Hebräischen heute für die beste, ${ }^{59}$ va. aufgrund des viel größeren assoziativen Sprachschatzes, den er durch sein intensives Bibelstudium erworben habe. Im Sprechen schätzt er sich im Deutschen und Hebräischen gleich gut ein, er hält in beiden Sprachen mühelos freie Vorträge. Diese Geläufigkeit führt er nicht zuletzt darauf zurück, dass auch er, wie die meisten Einwanderer seiner Generation, :u Hause noch Deutsch spreche. ${ }^{60}$ Ergänzt sei noch aus einer anderen Stelle des Gesprächs, dass auch Walk im Lesen, so wie alle, das Deutsche bevorzugt: es geht schneller! ${ }^{61}$

Für die „Durchschnittseinwanderer“ sind am ehesten die Berichte des Ehepaars Alsberg charakteristisch - wobei die hohe öffentliche Position Alsbergs als Staatsarchivar nicht zu vergessen ist! Auch Alsberg kann, wie Walk, auf Hebräisch und Deutsch freie Vorträge halten etc. ${ }^{62}$ Als seine Frau

sonst meist nur Angehörige der 2. Generation, von den Beispielen hier die Geschwister Ze'ev Walk (Bsp. 15, Z. 8 ff.) und Shoshana Stahl (Bsp. 16): vgl. zu Beispiel 15 auch Anmerkung 85 .

56 Bisher nicht publizierte Stelle; vgl. dazu Arielis Ausführungen zu einer „Weltkultur im Hebräischen" bei der jüngeren Generation, auch Schriftstellern wie David Grossman u.a., in Betten/Du-nour (2004, S. 296).

57 Unpublizierte Stelle aus dem Interview.

58 Vgl. nochmals die Statistiken in Kapitel 1.2. - Zu Arielis Sprachgebrauch und -einstellungen ausführlicher Schweiger (2011, S. 184 ff.).

59 Zu den folgenden Zitaten vgl. die gesamte Textstelle in Betten/Du-nour (Hg.) (2000, S. 107).

60 Dies mit seiner zweiten Frau, die auch eine Jeckin ist, während er mit seiner früh verstorbenen ersten Frau schon kurz nach der Einwanderung systematisch zum Hebräischen übergegangen war. Diese Tatsache befremdet seine Kinder aus der ersten Ehe (siehe unten Ze'ev Walk, Shoshana Stahl, Shulamit Melamed) sehr (vgl. Bsp. 12, Z. 6 ff.).

${ }_{61}$ Vgl. Betten/Du-nour (Hg.) (2000, S. 122, Z. 34 ff.).

62 Vgl. hierzu Paul Alsberg in Betten/Du-nour (Hg.) (2000, S. 110, Z. 21 ff.). 
Betti gesteht, dass sie auf Hebräisch eigentlich ïberhaupt nicht gelesen habe, erklärt er das damit, dass seiner Frau im Hebräischen die Assoziationen fehlen. ${ }^{63}$ Aber auch er selbst bekennt, bis heute keine Belletristik auf Hebräisch zu lesen, sondern v.a. auf Englisch - und um sprachlichen Genuss zu baben, bis beute nur auf Deutsch. ${ }^{64}$ Daher resümiert er für sie beide, sie seien nicht ins Hebrö̈sche bineingewachsen, ${ }^{65}$ Hebräisch sei nicht ihr kulturelles Erbe, nicht ihr kultureller Besitz, sondern (nur) die Sprache des alltäglichen Lebens (Bsp. 8, Z. 4 ff.). Auf meine Frage, ob er darunter leide (Z. 10), folgt zunächst ein selbstbewusstes Bekenntnis zu den kulturellen Gütern, die er mitgebracht habe (Z. $21 \mathrm{ff}$ ), und er bezeichnet seine Generation als viel reicher, spricht dann, schon abschwächend, von einem guten Gegengemicht (Z. 28) und schließlich heißt es nur noch: keineswegs nur als Verlust (Z. 29). Seine Frau geht jedoch weiter: Jetzt, am Ende ihres Lebenswegs, hat sie irgendwie das ... Gefiuhl ... ich bin bier fremd ( $\mathrm{Z} .31 \mathrm{ff}$.$) :$

\section{Beispiel 8: Paul Avraham und Betti Alsberg [79min 16s - 81min 21s]}

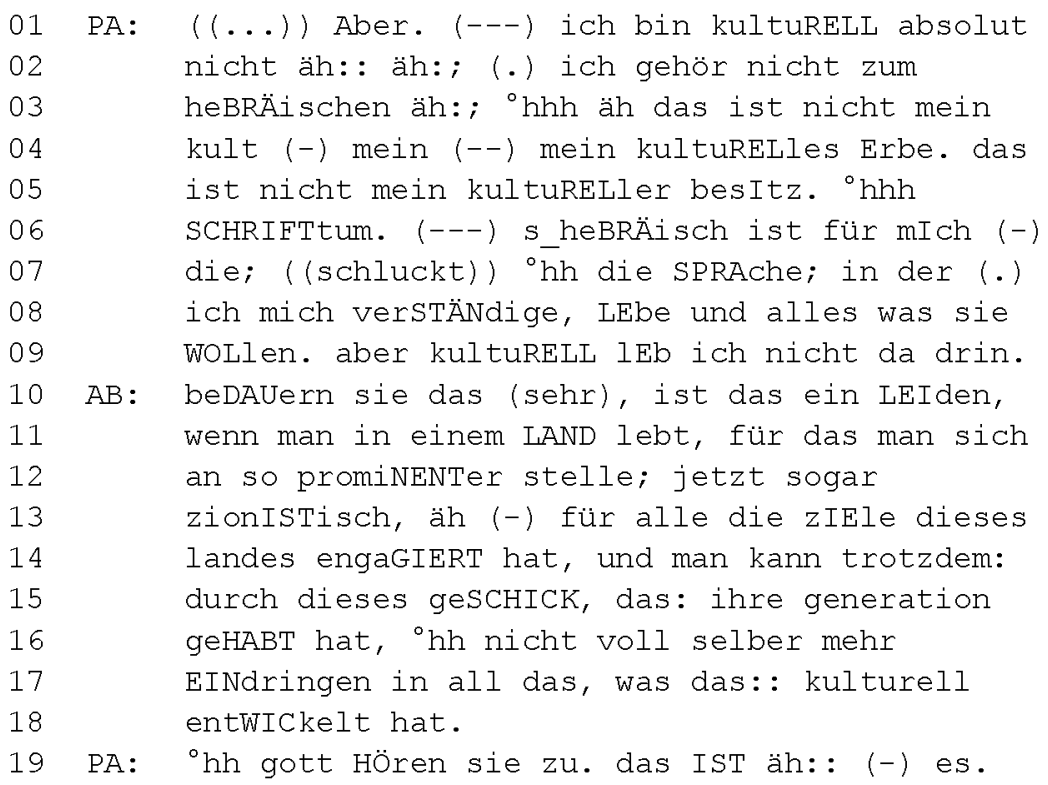

\footnotetext{
Vgl. Alsbergs in Betten/Du-nour (Hg.) (2000, S. 109 f., Z. 3 ff. und 17 ff.).

Vgl. dazu die Textstelle in Betten/Du-nour (2004, S. 326), deren „Kernsatz" Mit allem, was Hebräisch ist, sind wir an der Oberflache gebliaben ich schon in verschiedenen Publikationen zur Charakterisierung der Akkulturationsprobleme der Jeckes zitiert habe (z.B. in Betten 2011b, S. 216 f. und 2011c, S. 74). Alsbergs führen im Interview des Weiteren aus, dass sie (wie viele andere!) moderne hebräische Literatur in deutscher Übersetzung lesen, deutsche Zeitschriften und Rätselhefte halten, auf Deutsch scrabbeln etc.
}

65 Vgl. Betten/Du-nour (Hg.) (2000, S. 110, Z. 19 f.). 
(-) ich empfInd das manchmal als großen NACHteil. ${ }^{\circ}$ hh auf der ANdern seite, ${ }^{\circ} \mathrm{h}$ sind wir viel REIcher; ${ }^{\circ} \mathrm{h}$ an: äh: allgeMEInem; (--) äh: : (-) kulturellen (1.5) GÜtern. ${ }^{\circ} \mathrm{h}$ also_äh: äh: : : ${ }^{\circ} \mathrm{h}(-)$ das was uns TROTzdem; ${ }^{\circ} \mathrm{hhh}$ irgendwie hhh ${ }^{\circ}(---)$ ScHule; (-) Elternhaus in DEUTSCHland, ${ }^{\circ}$ hh literaTUR die wir lEsen; ${ }^{\circ} \mathrm{h}$ (--) BRINGT, (--) ist ein äh: absolut äh: : : gutes GEgengewicht. (--) bis HEUte. ${ }^{\circ} \mathrm{h}$ ich seh ich seh es kEIneswegs nur als verLUst an. (--) siehst du_s als verLUST an? (2.5)

$\mathrm{BA}$ : nein, $(\mathrm{x} x \mathrm{x} \mathrm{xxx}) \cdot{ }^{\circ} \mathrm{h}$ aber irgendwie: (.) ich hab doch das gefüHL, (-) ich:: (.) s: (-) ich BIN :. (.) i: (.) (ist mir)_äh. ${ }^{\circ}$ hh ich bin hier FREMD. ${ }^{\circ} \mathrm{h}$ ich kOmm mit der jugend nicht mehr MIT. (-) i (.) ich hab mit den (-) ich kann sie überhaupt nicht mehr verSTEH_n. ${ }^{\circ} \mathrm{h}$ jetzt besonders. (---) die entwicklung der (-) der der äh (-) der_äh der_äh: Jugend bei uns ist so, dass ich das geFÜHL hab; ${ }^{\circ} \mathrm{hh}$ NA, also $(--)$ weder die sPRAche noch dAs. (.) ich FRAG dich manchmal, (.) verSTEHST du das, was der da rEdet?

Betti Alsberg drückt damit aus, was viele Emigranten im Alter empfinden, wenn berufliche Kontakte und später erworbene Sprachkenntnisse wieder in den Hintergrund treten und auf die Erstsprache zurückgegriffen wird. ${ }^{66}$

Vergleicht man Paul Alsbergs Äußerungen, welche Rolle die hebräische Sprache für ihn spielt (die Sprache in der ich mich verständige, lebe und alles was Sie wollen, Z. 7 ff.), mit Arielis Beschreibung (Ich beherrsche die Gesellschaftssprache, die Umgangssprache, die Lehrsprache, und das hat mir geniggt ${ }^{67}$ ), so reduziert sich die Differenz zwischen ihnen hauptsächlich auf unterschiedliche Akzentsetzungen in ihrem (in beiden Fällen nicht schwerpunktmäßig hebräischen) kulturellen Selbstverständnis: Arieli verortet sich heute eher in einer Weltkultur mit (deutsch-englisch-)europäischer und amerikanischer Vermittlung, Alsberg hingegen weiterhin in seinem deutschen Kulturerbe.

Arieli nimmt in seine Argumentation noch eine Facette auf, die von den hier vorgestellten Personen nur Joseph Walk in seiner israelischen Identität verwirklicht hat: Er bedauert nämlich, dass ihm (mit seiner europäisch-weltlichen Prägung, siehe Bsp. 9, Z. 12f.) eine volle Teilhabe an der jüdisch-

\footnotetext{
o6 Vgl. u.a. die Interviews mit Ernst Siedner (Betten/Du-nour 2004, S. 329) und Elsa Sternberg (ebd., S. 331).

67 Textausschnitt aus Betten/Du-nour (2004, S. 293), unmittelbar dem in Anmerkung 53 angeführten Zitat vorangehend.
} 
hebräischen Sprach- und Lebenskultur (Z. $14 \mathrm{ff}$.) verwehrt blieb, weil er sich nicht genügend in das jüdlische hebräische Erbe (Z. 2f.), die traditional hebräische [.] oder religiös hebräische [.] Kultur vertieft habe (Z. 15 ff.). ${ }^{68}$

\section{Beispiel 9: Yehoshua Arieli [110min 53s - 112min 20s]}

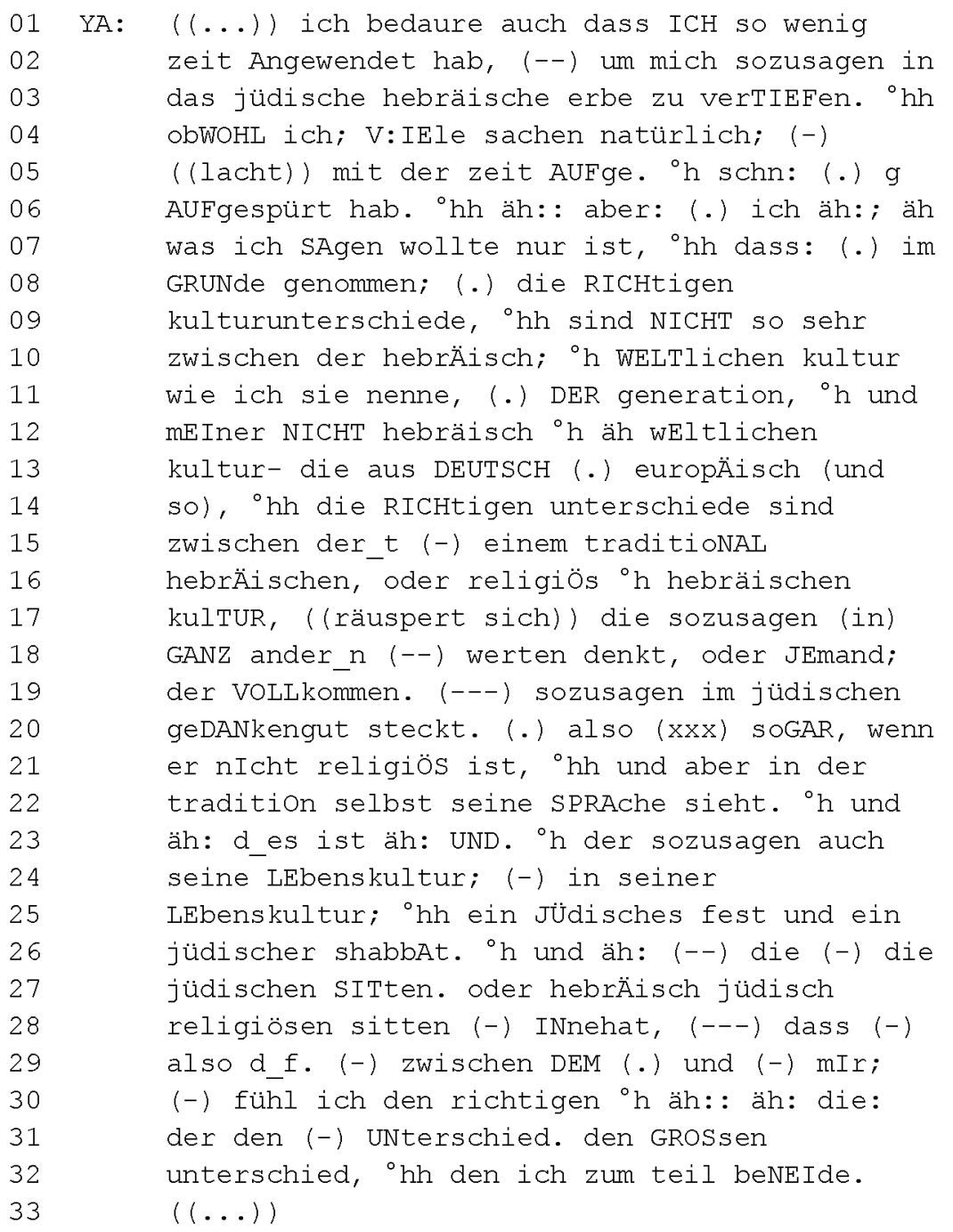

\footnotetext{
68 Vgl. diese Textstelle ausführlicher in Betten/Du-nour (2004, S. 293 f.); das gesamte Interview dreht sich, wie kaum ein zweites, um Überlegungen zu Kulturbegriffen und kultureller Zugehörigkeit.
} 
Während hier nur von einem Bedauern (und einem vermutlich relativ emotionslosen, eher intellektuell begründeten „Neidgefühl ${ }^{c,}$ Z Z. 32) angesichts mancher lebenslang nicht beseitigter Defizite die Rede ist, berührt die Lebensbilanz von Ada Brodsky die schmerzhaften irreparablen Schädigungen durch das Emigrationsschicksal. Auch sie war eine öffentliche Instanz unter den hebräischsprachigen Intellektuellen. ${ }^{69} \mathrm{Ganz}$ am Ende des Interviews bat sie, noch einen Nachtrag machen zu dürfen. Nach allgemein gültigen Abwägungen, bis zu welchem Alter bei der Einwanderung eine vollständige Akkulturation an einen neuen Kulturkreis für Migranten erreichbar ist bzw. unter welchen Bedingungen (wie in ihrem persönlichen Fall) eine volle Teilhabe an zwei Kulturen in zwei gleichwertig beherrschten Sprachen möglich ist, macht sie doch eine gravierende Einschränkung: Eine noch tiefere - ihr offensichtlich im Lebensrückblick wünschenswerte - Verwurzelung $(Z .34 \mathrm{ff} .)^{70} \mathrm{im}$ fraglos als Heimat betrachteten Immigrationsland wäre nur möglich gewesen, wenn sie in noch jüngeren Jahren gekommen wäre (Z. $30 \mathrm{f}$.): dann allerdings um den Preis des (vollen) deutsch-europäischen Kulturerbes ( $\mathrm{Z} .31 \mathrm{ff}$.), in dem sie stattdessen ihre berufliche und persönliche Erfüllung gesucht hat: ${ }^{71}$

\section{Beispiel 10: Ada Brodsky [82min 29s $-84 \min 17 \mathrm{~s}]$}

$01 \mathrm{AB}:((\ldots))$ ich hatte immer das gefïHL gehabt. (-)

02

03

04

05

06

07

08

09

10

11

12

13

14

15
VIEle viele jAhre, (-) ${ }^{\circ} \mathrm{h}$ dass ich: $\mathrm{zu}$ einem ideAlen zeItpunkt. (-) von mei (-) von !MEI!ner entwicklung aus. ((klopft sich auf die schenkel)) ${ }^{\circ} h$ äh aus DEUTSCHland weggegangen bin; ${ }^{\circ}$ hh das heißt (--) ich habe (--) die: (-) ich habe die: äh die kultur in mir geHABT schon, (.) ich war alt geNUG, (--) ich war schon in der oberTERtia auch, also ich war alt geNUG, ${ }^{\circ}$ hhh um für mein LEben lang; äh: : äh: diese äh diese kultur (--) äh äh zu (-) zu beHALten. (ne). ${ }^{\circ}$ hh und auch äh äh FORTzuführen nicht? (ich war) ( $x x x$ ) genug baSIERT, und doch noch jung geNUG, ${ }^{\circ}$ hhh um eine richtige israElin zu werden. und auch mit

69 Nach ihrem Tod hieß es in einem Nachruf in Israels führender Tageszeitung Ha'aret vom 22.04.2011, sie hätte den Israel-Preis bekommen, wenn sie mehr Ellbogen gehabt hätte; am 03.06.2011 widmete ihr der Ha'aretz eine Wochenendbeilage. - Vgl. zu Brodsky ausführlicher Schweiger (2011); Jessen (2011); Betten (ersch.demn.).

70 Zur häufigen Verwendung der Wurzel-Metapher im Israelkorpus siehe Thüne/Leonardi (2011, S. 232-239).

${ }^{71}$ Vgl. dieselbe Stelle, leicht überarbeitet, in Betten/Du-nour (2004, S. 292 f.). 
16 der hebrÄischen sprache (--) äh: mich ganz:

17 (.) zu verSTÄNDigen. ${ }^{\circ} \mathrm{hh}$ und mich: äh na_au

18 nicht für ein_n (.) m_i_meine ich war_äh (-)

19 schlIEßlich doch noch KIND, als ich HERkam.

20 NICHT? und (.) bin noch in die scHUle

21 gegangen, und und und die ganzen ${ }^{\circ} \mathrm{hhh}$

22

23

24

25

26

27

28

29

30

\subsection{Vergleichendes Resümee}

Vergleicht man die wichtigsten Befunde, so ist z.B. aufschlussreich, dass nicht nur Paul Alsberg, der bei der Immigration schon Student war, sondern auch der früher und ohne äußeren Zwang eingewanderte Yehoshua Arieli ihre Beziehung zur hebräischen Kultur, trotz sehr guter Sprachbeherrschung und glänzender Berufslaufbahn, als eine oberflächliche bezeichnen. Ada Brodsky, die erfolgreich im hebräischen Kultursektor gearbeitet (aber dort v.a. europäische Kultur vermittelt) hat, kommt zu dem Ergebnis, sie hätte noch tiefer verwurzelt sein müssen, um z.B. ihren Lebenstraum des schöpferischen Schreibens realisieren zu können. Joseph Walk zeigt einerseits eine starke (im Alter auch berufliche) Bindung an das deutsche Judentum, fühlt sich aber aufgrund seiner religiösen Bildung und Bindung auch ganz ins Hebräische integriert: die religiöse (kollektive) Tradition, deren mangelhafte Kenntnis nach Arielis und Brodskys Selbstanalyse ihnen die vollständige Integration in die hebräisch-jüdische Kultur verwehrt, scheint bei Walk wesentliche Grundlage seiner (subjektiven) Integrations- und Akkulturationseinschätzung (und Zufriedenheit) zu sein. 
Keinerlei Diskussion über ihre Akkulturation lässt hingegen Leni Yahil $\mathrm{zu}^{72}$ Sie berichtet weder von Problemen bei der grundlegenden Änderung ihrer identitären Ausrichtung noch von der Suche nach Alternativen in den Anfangsjahren nach der Immigration: Ihre zionistische Grundhaltung als Korrektur zu der Geschichte ihrer assimilierten Familie und die sozialistische Einstellung im Gegensatz zu ihrer mit der Assimilation verbundenen großbürgerlichen Herkunft bleiben bis zuletzt ihre identitäre Leitlinie. Bei ihr scheint ein Identitätskonzept zugrunde zu liegen, nach dem die Identität einer Person als „Aspiration“, ,als etwas Aufgegebenes" (und nicht Gegebenes) erscheint (siehe Straub 2004, S. 279), während alle anderen die Offenheit und Veränderbarkeit ihrer neuen Identität erkennen lassen und auch die Problematik ihrer jeweiligen Entscheidungen erörtern. Obgleich anzunehmen ist, dass (gerade?) auch bei Yahil (viele?) Relikte ihrer Herkunftskultur (z.B. in Form von Einstellungen, Prinzipien) auf ihre neue Identität Einfluss genommen haben (so auch auf die Wahl ihres akademischen Berufsweges, der bei der "Inszenierung" ihrer narrativen Identität im Interview eine wesentliche Grundkonstante darstellt), werden diese Teile ihrer Identität nicht thematisiert bzw. zugelassen. ${ }^{73}$

\section{Die 2. Generation}

\subsection{Zur Repräsentativität der Beispielauswahl}

Die Probleme der 2., bereits in Erez Israel geborenen Generation, von denen viele ihre Primärsozialisation in deutscher Sprache erfuhren, sind, wie schon in Kapitel 1 angedeutet, ganz anderer Art als die ihrer Eltern. Der automatische Erwerb des Deutschen als erste Sprache öffnete nur in verein-

\footnotetext{
72 Sie bemerkte einmal, dass sie an unserem Projekt va. in der Absicht teilgenommen habe, um die nostalgischen Äußerungen anderer alter Jeckes zu korrigieren, und war entsprechend unzufrieden mit dem Gesamttenor unserer Textauswahl in Wir sind die Letoten. Fragt uns ans (Betten/Du-nour 2004), die die Darstellung der unterschiedlichen Äußerungen und Einstellungen zum Ziel hatte.

73 Vgl. auch die Analyse von Schweiger (2011). Auffällig ist z.B. bei der Pronominalanalyse des Interviews, dass Yahil zwar erwartungsgemäß oft das kollektive Wir im Zusammenhang mit ihrer politischen Arbeit benutzt, aber doch viel mehr als andere durch eine prononcierte Verwendung von $i c h$ sich v.a. in entscheidenden beruflichen Situationen als selbstständig Handelnde darstellt. Interessant ist der Vergleich mit der Analyse schriftlicher jüdischer Autobiographien von Malo (2009): Zu Gershom Scholems Autobiographie Von Berlin nach Jerusalem (1977), in der dieser den Weg von seinem assimilierten Elternhaus zum Zionismus als einen geradezu zwangsläufigen beschreibt, merkt er an, dass Scholem (dennoch) großen Wert darauf lege, „die Autonomie seiner intellektuellen Entwicklung zu betonen. In den diesen Teil seiner Persönlichkeitsentwicklung behandelnden Abschnitten lässt sich auch eine deutliche Nähe zum Typus der Gelehrtenautobiographie konstatieren“" (S. 168.). Die Parallelen zu Leni Yahils Selbstdarstellung sind nicht zu übersehen und zeugen von Identitätsmustern, die durchaus noch aus der „alten Welt“ stammen.
} 
zelten Fällen über das Vergnügen an deutschsprachigen Kinderbüchern hinaus (an die sich viele auch heute noch gern erinnern) den Weg zur späteren Rezeption der grundlegenden literarischen und philosophischen Werke der (klassisch-humanistischen) deutschen Kultur, auf die sich der Kulturbegriff und die kulturellen Vorlieben ihrer Eltern gründeten. ${ }^{74}$

Ein Blick auf die Kinder unserer Repräsentanten der 1. Generation erweist sich als durchaus geeignet, einige charakteristische Entwicklungsmuster der 2. Generation zu illustrieren. Yehoshua Arieli und Ada Brodsky hatten keine deutschsprachigen Ehepartner, ihre Kinder besitzen keine aktive Sprachkompetenz im Deutschen. Bei Leni Yahil wurde Deutsch bewusst nicht als Familiensprache benützt, obwohl ihr aus der Tschechoslowakei stammender Ehemann auch deutschsprachig war. Ihre Kinder erwarben aber bei der zweijährigen Auslandsmission der Eltern in Bonn doch Deutschkenntnisse, zumal eine Tante aus Deutschland in dieser Zeit bei ihnen lebte; daher war es dem Sohn, der heute als Universitätsprofessor in Amerika lebt, möglich, seine Deutschkenntnisse rasch zu verbessern, als er sie beruflich brauchte. (Dies ist auch bei anderen ,Jeckeskindern" gar nicht so selten vorgekommen.)

Im Folgenden werden nun vier Interviews mit den Kindern der Interviewpartner Paul und Betti Alsberg sowie Joseph Walk herangezogen, die Deutsch noch als Familiensprache benutzt haben. Die beste Sprachkompetenz hat die Tochter von Alsbergs, die mit ihrer Mutter bis heute Deutsch spricht (vgl. Bsp. 11, Z. 27 ff.). Die drei Kinder aus der ersten Ehe von Joseph Walk hingegen haben, seitdem sie das Elternhaus verließen, fast kein Deutsch mehr gesprochen. Trotz äußerlich gleicher Ausgangsbedingungen ist ihre heutige Sprachkompetenz sehr unterschiedlich. Die Aufnahmen stel-

\footnotetext{
In meinen bisherigen Publikationen zu den Interviews mit der 2. Generation habe ich allerdings bereits auf einige Ausnahmen hingewiesen, meist von Kindern, die auch noch wäh rend ihrer Schulzeit ein so affirmatives Verhältnis zu ihrem Elternhaus hatten, dass sie dessen Werte auch gegen die Anfeindungen der Umwelt akzeptierten als eine, wenngleich ganz andere Komponente neben ihrer hebräisch-israelischen Kultur, in die sie durch Schule, Jugendverbände, Studium sowieso ganz selbstverständlich hineinwuchsen: Vgl. etwa die Beispiele von Prof. Tom Lewy, Dr. Chanan Tauber und Nurit Lieber-Leffmann (in Betten 2010, 2011a, b), die es immerhin bis zur Rezeption der Buddenbrooks oder gar von Goethes Faust und Brecht in deutscher Sprache brachten; Ähnliches berichteten sie und andere (noch flieBend Deutsch sprechende) Teilnehmer/innen bei zwei Roundtable-Gesprächen, die ich 2008 in Jetusalem (siehe Betten 2011b, S. 227) und 2012 im Goethe Institut Tel Aviv moderierte (Aufzeichnungen am Deutschen Spracharchiv, siehe Anm. 11). Allerdings wurden den meisten diese Kenntnisse bei Vorlesungsabenden ihrer Eltern nahe gebracht, weniger durch eigene Lektüre (vgl. Anm. 81). - Dennoch darf beim Blick auf diese Ausnahmen, denen die Kultur des Elternhauses noch zur Bereicherung wurde, nicht übersehen werden, dass es auch Kinder gab, die aufgrund der deutschen Familiensprache und mangelhafter Beherrschung des Hebräischen beim Schuleintritt zunächst sprachliche Probleme bekamen, die sich in schlechten Schulkarrieren weiter auswirken konnten. Die oft generationenalte intellektuelle Identität von Familien wurde auf diese (nicht wie z.B. im Kibbuz ideologisch bedingte) Weise unterbrochen und damit oft auch ihr sozialer Abstieg in der nächsten Generation besiegelt.
} 
len daher einen Idealfall zum Studium der Variablen dar, die auf die Sprachbewahrung Einfluss nehmen. ${ }^{75}$ Ihre Analyse liefert wertvolle Daten über den Zusammenhang von öffentlichem Sprachprestige, individuellen Spracheinstellungen und damit verbundenen Sprachkompetenzen. ${ }^{76}$

Die vier Beispiele können durchaus als exemplarisch für einen Großteil der Interviews mit der 2. Generation betrachtet werden.

3.2 Der Erwerb der deutschen Sprache in der Kindheit:

Reinszenierung und Anekdotisierung

Alsbergs Tochter Irit Ovadia spricht fließend und grammatisch weitgehend einwandfrei Deutsch. Ihr Vater rechnet sie intellektuell zu unserem Kreis, d.h. der Jeckes und ihrer Organisationen und deren kultureller Prägung - wenngleich transformiert ins Hebräische. ${ }^{77}$ Die Tochter, von Beruf Englischlehrerin und Leiterin eines Konservatoriums, hat, wie alle Kinder, deren Großeltern noch auswandern konnten, ihr Deutsch hauptsächlich von ihnen als Sprechsprache gelernt ${ }^{78}$ und auch beim Sprechen in der Öffentlichkeit - im Gegensatz zu den meisten anderen - keine Hemmungen entwickelt (siehe Z. $21 \mathrm{ff}$.$) :$

Beispiel 11: Irit Ovadia [0min 52s - 1min 17s, 45min 47s - 46min 14s]

01 IO: meine eltern kamen neunundDREISsig nach äh:

02 palästina, ${ }^{\circ}$ hh aber das haben sie_s schon

03

04

05

06

07

08

09

10

11 sicher geHÖRT, die geschichte von meinem vAter. ${ }^{\circ}$ hh von meinen ELtern. (--) und äh mein vater war noch stuDENT, (---) in unserem beFREIungskrieg, (-) meine mutter Arbeitete schon als KRANkenschwester, ${ }^{\circ}$ hh und_äh:: (-) ich wurde großge_f_gezogen von meinen GRosseltern, ${ }^{\circ} \mathrm{h}$ das mit uns zuSAMmenlebt, (.) in einem hAUs in jeRUsalem, [Auslassung: 43min 30s]

75 Ähnliche Beobachtungen machte Eller (2010, S. 154 f.) bei Kindern von Flüchtlingsfamilien aus Böhmen: „Bemerkenswert ist, dass vielmals innerhalb eines Geschwisterverbandes, obwohl sie unter gleichen Bedingungen sozialisiert wurden, enorme Unterschiede bestehen“; dies bezieht sich auf die sprachliche Kompetenz der Einzelnen bzw. ihren Sprachabbau, wobei die „Abkehr von der ehemaligen Primärsprache“ bzw. Familiensprache (oder aber ihr Ethalt) die unterschiedlichsten Gründe haben kann. - Zu diesem Thema im Zusammenhang mit meinem Korpus vgl. ausführlich Betten (2010) und (2011a).

${ }_{76}$ Vgl. schon Betten (2011a).

77 Siehe die Textstellen von Paul Alsberg in Betten/Du-nour (Hs:) (2000, S. 110, Z. 43 ff.) und Betten/Du-nour (2004, S. 349 f.).

78 Allgemein zur wichtigen Rolle von Großeltern als „Adiuvanten " beim Spracherwerb der Kinder von Migranten vgl. Eller (2010, S. 159 f.). 


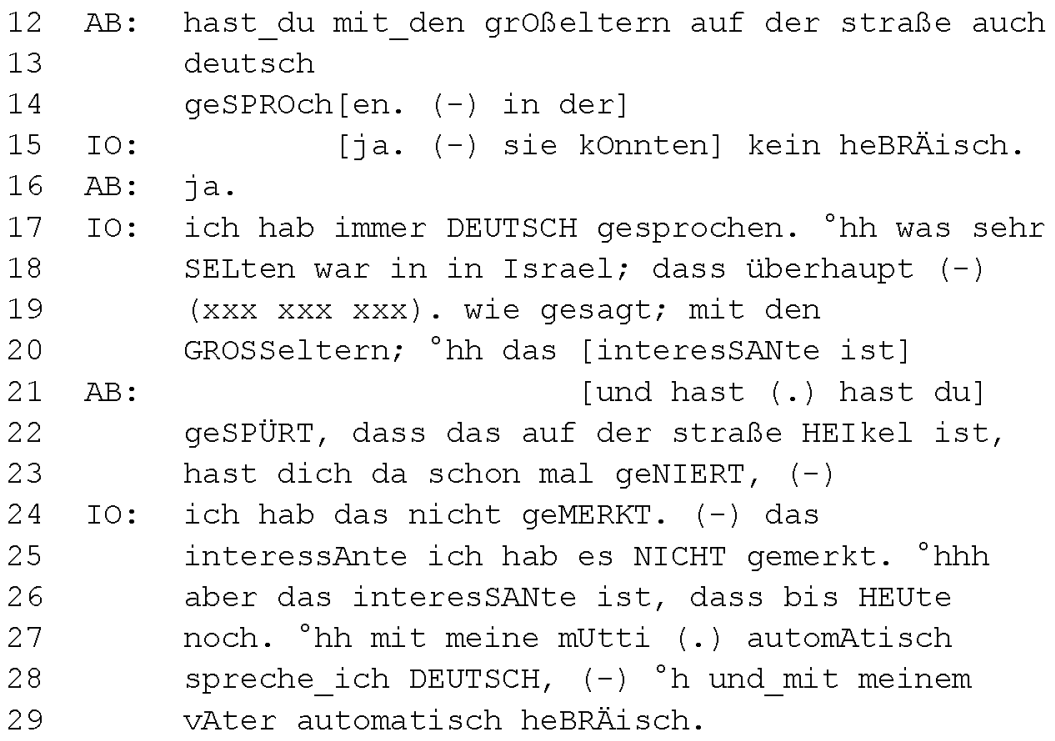

Auch die Kinder von Joseph Walk haben hauptsächlich mit den in ihrem Hause lebenden Großeltern väterlicherseits Deutsch gesprochen. Ihre Sprachkompetenz heute ist jedoch, wie bereits gesagt, sehr unterschiedlich.

Am gebrochensten spricht die jüngere Schwester Shulamit, die als junge Erwachsene, als die Familie nach dem Tod der Mutter und der Wiederverheiratung des Vaters auseinanderbrach, beim Studium in Jerusalem in ultraorthodoxe Kreise geriet, in denen sie heute nicht nur als Frau des Rabbiners wirkt, sondern auch als politische Aktivistin der nationalistischen Siedlerbewegung, wodurch sie politisch in absoluten Gegensatz zu ihrem liberalen, in der religiösen Friedensbewegung engagierten Vater geraten ist, was für beide sehr schmerzvoll war. ${ }^{79}$ Die Verurteilung des Lebens in der Diaspora, voran des assimilierten deutschen Judentums, hat in Fällen wie bei Shulamit zwangsläufig einen radikalen Bruch mit dem familialen Herkunftsmilieu zur Folge, und oft kommt es dann auch zur weitgehenden Verdrängung der damit verbundenen Sprache ${ }^{80}$ Dennoch präsentiert sich die Interviewte nicht

\footnotetext{
Vgl. Anmerkung 48.

80 Zu einem weiteren, ähnlichen Fall in meinem Korpus vgl. Betten (2011a, S. 74ff.). Zu diesem Phänomen der Aufgabe familialer Traditionen speziell bei freiwillig zur Orthodoxie übergetretenen jüdischen Frauen vgl. Inowlocki (1999). - Ich spreche hier jedoch bewusst von "Verdrängung", nicht unbedingt von Sprachverlust/attrition: Obgleich die aktive Sprechfähigkeit stark eingeschränkt ist, beweist die rasche, gute Interaktion, die fast nie durch durch Verstehensprobleme der fast bis zuletzt konsequent deutschen Gesprächsbeiträge der Interviewerin beeinträchtigt wird, dass Shulamits passive Sprachkompetenz wesentlich größer ist. Dies traf für mehrere Jeckeskinder zu, die ihre Interviews lieber auf Englisch geben wollten, aber doch das meiste auf Deutsch noch verstehen. - Zum Unterschied von Sprachvergessen und Sprachverlust vgl. Riehl (2009, S. 85 ff.).
} 
konsequent im Sinne der von ihr zu erwartenden Haltung: So zeigte sie sich sehr enttäuscht, dass sie so schlecht sprach - wo sie einst der Stolz der Großeltern war und sich sogar Lesen beibringen ließ (siehe Z. 57 ff.), was eine große Ausnahme darstellt: ${ }^{81}$

\section{Beispiel 12: Shulamit Melamed [60min 45s $-63 \mathrm{~min} 9 \mathrm{~s}$ ]}

$01 \mathrm{AB}$ : und äh: : (--) also (-) solAnge die großeltern

bei euch im HAUS waren, (.) war das dann (.) ein sprachlichs_äh: gemISCHtes haus. (.) die oma hat immer DEUTSCH gesprochen, =

SM: $=$ naCHON ${ }^{82}$

$A B$ : und äh: ihr habt (--) M:IT ihr deutsch gesprochen, und_n ah (.) mit dem $v$ (-) mit den eltern: (-) schon heBRÄisch immer, (-) nicht?

SM: N[UR: : iwr]it. (-) [THEY they;] (-)

$\mathrm{AB}: \quad[j a,($.$) ja.] (-) [deine mutter hat]$

SM: they äh: spoke (.) äh (.) iwrIt (-) BETter than us.

$A B: j a$.

SM: [VEry.]

AB: [auch die MUTter.]

SM: AH.

$A B:$ ja. (-) [ja?]

SM: [she] was WoNderful_g. in grAmmar of hebrew she was_äh !MUCH! more than äh:; sh:e; ${ }^{\circ} \mathrm{h}$ HELPed me: in the: : (-) homework. [Auslassung: 36s]

SM: my FIRST äh sEntence; (--) that i SPOKE, it was (-) FEIN (-) höschen anzieh_n. (--) [GERmany • ]

$A B:$ [was (XXX XXX) FEIN?]

SM: fEIn (-) HÖschen.=

AB: =fein Höschen. haha [haha.]

SM: [anzieh_n.] (--)

Auch von den sehr gut und flüssig Deutsch sprechenden „Kindern“ können die wenigsten lesen und noch weniger schreiben, was z.T. durch das ganz andere Schriftsystem des Hebräischen, das als erste Schreib- und Lesesprache erlernt wurde, bedingt ist, v.a. aber durch den Mangel an Motivation (und schulischen Möglichkeiten!), sich mit der nolens volens zu Hause erlernten deutschen (Sprech-)Sprache weiter zu beschäftigen. Erst als Erwachsene versuchten sich einige Wenige zu Studien- oder Berufszwecken auch Grundkenntnisse im Lesen und Schreiben anzueignen. (Von den in Betten 2011a präsentierten „Fallstudien“ gehören zu den Ausnahmen der Arzt Chanan Tauber, die Verlagslektorin Ariella Shkedi und der Journalist David Witzthum).

${ }^{82}$ Hebr. nachon: Zustimmungspartikel (dt. ,richtig', genau (so ist es)', , stimmt'). 
So_(OKAY). it was the first äh: : (.) äh sentence that $i$ SPOKE. $(1,5)$

$A B$ : haha haha.

SM: and äh: : (-) sAba (or) (-) oder SAVta; ${ }^{83}{ }^{\circ} \mathrm{h}$ they_l (-) they LAUGHED; (.) when we: : (--) dId a misTAKE. ${ }^{\circ} \mathrm{hh}$ and $\operatorname{Ima}^{84}$ told (-) if they spoke GERmany, (-) then i once_äh: spoke_äh: (-) WELL; and spoke corRECT. (.) so ${ }^{\circ} \mathrm{h}$ COrRECT them. but SAVta; ${ }^{\circ} \mathrm{h}$ LOVED the: : ${ }^{\circ} \mathrm{h}$ the little äh: : (-) mistAke. (-) and so i think my GERmany is like a; (--) a LANGuag, (-) LANGuage $?=$

Der erste Satz, den sie sprach, war ein deutscher (siehe Z. $22 \mathrm{f}$.) - und in diesem Textausschnitt bleibt er ihr einziger Beitrag auf Deutsch, wird aber mit großem Vergnügen zitiert.

Die beiden Enkelinnen haben seinerzeit den Großeltern sogar Briefchen und Karten auf Deutsch geschrieben, allerdings mit hebräischen Lettern, wozu Vater und Töchter verschiedene Anekdoten beisteuerten. Die

83 Hebr. saba: ,Großvater ${ }^{c}$, savta: , Großmutter ${ }^{c}$.

84 Hebr. ima: ,Mutter'. 
Tendenz zur anekdotischen Wiedergabe von Episoden aus der jeckischen Kindheit, aus der sich früher oder später jeder abzulösen und ein neues, besser ins Land passendes Identitätskonzept zu finden hatte, ${ }^{85}$ ist bei der 2. Generation ausgeprägt - sofern nicht das Bedürfnis besteht, ernsthaft über die erheblichen Identitäts- und Loyalitätskonflikte zu sprechen, in die sehr viele Jeckeskinder gerieten, wenn sie wegen der Eigentümlichkeiten ihrer deutsch-geprägten Elternhäuser gehänselt wurden, und va. wenn sie später von den Verbrechen erfuhren, die im Herkunftsland ihrer Eltern begangen wurden. ${ }^{86}$ Thre Familiensprache bzw. Erstsprache war außer Haus tabuisiert, verhasst - viele wuchsen mit Scham auf und versuchten die jeckische Identität vollkommen abzustreifen. ${ }^{87}$ Dies gilt auch für den ein Jahr älteren Bruder von Shulamit, Ze'ev Walk. Er hatte als Junge in dem Dorf, wo ihr Vater Lehrer war, besonders zu leiden. ${ }^{88}$ Er versuchte nach seinem Schulabschluss alles Jeckische hinter sich zu lassen und in einem Kibbuz das zu werden, was damals unangefochtenes Ideal des Landes war, nämlich ein Pionier, der mit der Hände Arbeit das Land und den jüdischen Staat aufbaut. ${ }^{89}$ Die ungeliebte Herkunftsidentität verdrängte auch er: Er heiratete eine aus Polen stammende Jüdin und war besonders erfreut, wenn man ihn mit seinem sonnenverbrannten Teint für einen orientalischen Juden

25 Eine weitere Rolle spielt hier natürlich auch der Zusammenfall des „,sozial wirksame[n] Mythos vom neuen Israeli [...] mit den Bedürfnissen der Adoleszenten", sich vom Elternhaus zu lösen und einen eigenen Lebensweg zu verfolgen (Rosenthal/Völter/Gilad 1999, S. 49 f.). In meinen Interviews mit der 2. Generation werden die Konfrontationen mit den Eltern aus dieser Phase im Rückblick oft als quasi anekdotische, lebhafte Erzählungen inszeniert, die gleichzeitig starken Rechtfertigungscharakter haben (mit Beispielen Betten 2007b, S. 107 ff.).

86 Interessant im Vergleich sind hier die sprachbiographischen Untersuchungen und analytischen Überlegungen von Busch (2010) zum Spracherleben von Kindern, die aus Krisengebieten geflohen sind: „Erst im Nachhinein, dadurch dass das persönliche Erlebnis in einem sozio-historischen Kontext situiert wird, der die Konnotation ethnischer Konflikte und sprachlicher Trennungen trägt, wird ihm seine eigentliche Bedeutung verliehen" (S. 69). Ganz entgegengesetzter Art scheint zunächst die Sehnsucht nach einer Erstsprache zu sein, die als gewaltsame De-Propriation/Sprachberaubung erlebt wurde und, wie von Busch am Beispiel des israelischen, aus der Bukowina stammenden Autors Aharon Appelfeld exemplifiziert, „präbabylonische Phantasien "c mobilisieren kann (ebd., S. 76 ff.). Allerdings könnte man überlegen, ob die plötzliche „Sinnesänderung“" vieler Angehöriger der 2. Generation, die im Alter, nach dem Verlust der Eltern, die deutsche Sprache als Familiensprache durchaus wieder mit positiven Gefühlen verbinden und vereinzelt sogar als „,wärmste " Sprache empfinden (siehe unten zu Bsp. 16), auch wieder Elemente dieser Sehnsucht nach der „, heilen Weltc der Kindheit enthält und daher psychologisch ähnlich zu deuten ist.

87 Vgl. dazu die ausführlichen Textbeispiele aus dem Interview mit Tom Lewy, siehe Anmerkung 2.

${ }_{88}$ Vol. nochmals Anmerkung 2. (Zu der nur auszugsweise zitierten Stelle mit einer Schilderung, warum es für ihn als Kind so schlimm war, als Jecke poto beschimpft zu werden, siehe ausführlich Betten 2011a, S. 65 ff. und 2011b, S. 222 f.)

89 Vgl. Śegev (2008, Kap. 9, bes. Zitate S. 339 ff.). Hier gibt es auch Parallelen zu den Identitätsidealen der noch jugendlichen Einwanderer der 1. Generation, siehe Kapitel 2 zu Arieli und Brodsky. 
hielt. ${ }^{90}$ Auch sein Deutsch ist stark pidginisiert, wenngleich nicht so stark wie bei seiner Schwester Shulamit. Auch er behilft sich mit häufigem CodeSwitching zu einem ebenfalls fehlerhaften Englisch (da die Interviewerin kein Hebräisch versteht). ${ }^{91}$ Wiederum etwas anekdotisch, wies er darauf hin, dass er schon als Kind die Sprachen gemischt habe, indem er z.B. deutsche Wörter mit hebräischen Flexionsendungen versah:

\section{Beispiel 13: Ze'ev Walk [51min 12s - 51min 36s]}

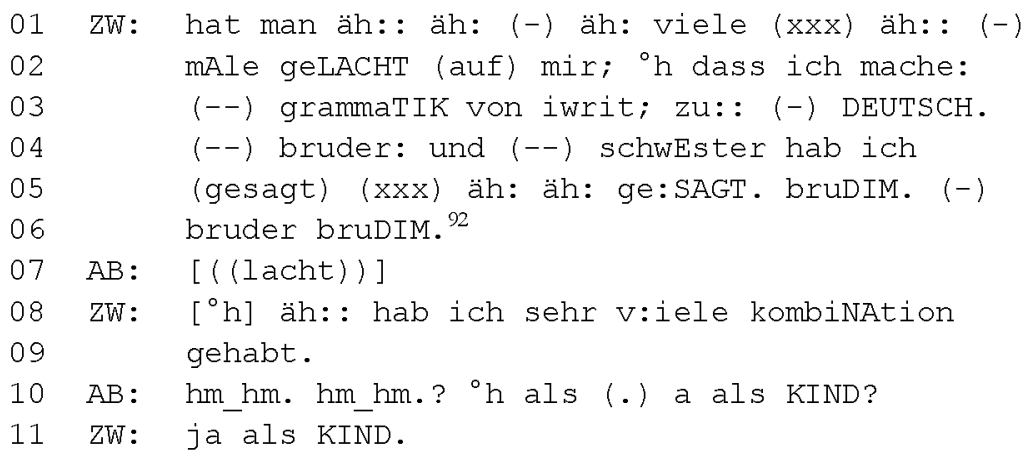

Diesen Hinweis kann man vermutlich auch als Ausdruck seines Selbstverständnisses bzw. Wunsches sehen, nie ein ,richtiges" Jeckeskind gewesen zu sein. ${ }^{93}$

Interessant wird seine bei vielen Angehörigen der 2. Generation ähnlich anzutreffende Restkompetenz des Deutschen aber erst im Vergleich zu seiner Zwillingsschwester Shoshana. Sie spricht wesentlich besser, wohl weil sie eine positive Beziehung zur Sprache selbst hat: dies nicht nur, weil sie als hübsches Mädchen in der Schule weniger zu leiden hatte als ihr Bruder, sondern gewiss auch, weil Deutsch für sie die Sprache der geliebten, früh verstorbenen Mutter war und sie sich von jeckischen Sitten zu Hause niemals distanzierte: ${ }^{94}$

90 Seine Zwillingsschwester Shoshana kommentierte in ihrem Interview Aussagen ihres Bruders wie diese amüsiert mit der Bemerkung: und dabei ist er doch so ein Jecke!

91 Bei seiner Schwester wiederum, die überwiegend Englisch sprach (siehe Bsp. 12), erfolgt ein Code-Switching vom Englischen zum Deutschen am ehesten an Stellen, wo von der Familie, den Großeltern oder aber von jeckischen Gewohnheiten (Ordnung, Sauberkeit etc.) die Rede ist, an denen sie festgehalten hat. Zu dieser Art von funktionalem/situationellem CodeSwitching (siehe Riehl 2009, S. 32 f.) macht u.a. Eller (2010, S.161) ähnliche Beobachtungen bei thren Migranten-Interviews.

92 Hebr. -im: Pluralendung für Maskulina.

93 Vgl. Treichel (2004, S. 21) mit einer Fallstudie, wo sich ,biographietheoretisch gesprochen“ „während der Schulkarriere ein Erleidenspotential aufgebaut ${ }^{c c}$ hat, das den Informanten fortan sprachlich blockiert.

94 Mehrheitlich sind es die Frauen, die ausführlich und positiv über die Weitergabe, kulturelle[r] Versatzstücke sowie Gewohnheiten und Erinnerungen“ in der Familie sprechen: Die von 
Beispiel 14: Shoshana Stahl [106min 48s - 107min 30s]

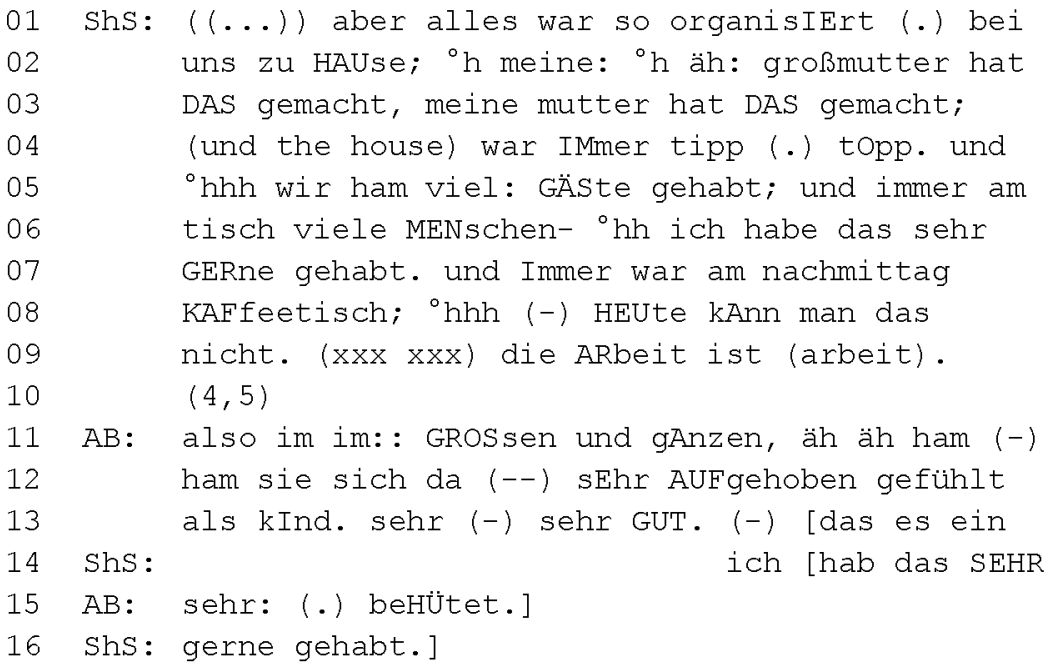

Eventuell wird Shoshanas positive Einstellung zu den familialen Lebensformen dadurch unterstützt, dass ihr aus Holland stammender Ehemann kulturell vom Elternhaus nicht so verschieden war - auch wenn dieser seine guten Deutschkenntnisse als Kind in drei Konzentrationslagern erworben hatte, so dass die Eheleute auf Reisen Deutschland lange aussparten. Mit ihrer Schwiegermutter aber verständigte sich Shoshana auf Deutsch.

Strutz (2006) bei jüdischen Emigrantenfamilien in den USA gemachten Beobachtungen finden sich ausnahmslos auch in meinen Interviews: „alltägliche Handlungen wie z.B. das Kochen, das Vorsingen von [...] Kinderliedern, das Vorlesen aus deutschen Kinderbüchern, [...] die Art sich zu kleiden, [...] Tischmanieren oder auch [...] Anregungen zur Beschäftigung mit europäischer Musik und Literatur" (Zitate S. 263 f.). Ebenso bestätigt sich, dass „,der emotionale Wert von Essen und Kochen" (ebd., S. 263) besonders groß ist: Selbst Shoshanas orthodox gewordene Schwester Shulamit führt stolz aus, dass ihre Küche heute noch berühmt sei für Kartoffelsalat, Klöße, Streuselkuchen, Pudding u.ä.m. (dies im Kontrast zu der aus Russland stammenden Familie ihres Mannes). - Zur identitätsstiftenden Funktion des Erzählens von „Dingen“, an die Erinnerungen an „früher ${ }^{c c}$, die „alte Welt ${ }^{\text {cc }}$ geknüpft sind, und zu ihrer „Bedeutung für die, self-regulation' (im Sinne des Über-Sich-Nachdenkens) und die Selbstdarstellung ${ }^{c c}$ vgl. Thüne (2009, Zitat S. 203). Thüne zieht v.a. das Korpus der 1. Generation heran, doch auch in den Interviews mit der 2. Generation ist oft von „Dingen“ mit metonymischer Funktion die Rede, die an die nächste(n) Generation(en) weitergegeben wurden. 
3.3 Spätere Einflussfaktoren auf die Einstellungen zur deutschen Sprache und Kultur und deren Zusammenhang mit der heutigen Sprachkompetenz

Abschließend sollen nun noch die Zusammenhänge der identitären Orientierung der 2. Generation mit ihrem heutigen Verhältnis zur deutschen Sprache und Kultur und zum heutigen Deutschland kurz angesprochen werden.

Die jüngere Walk-Tochter Shulamit und ihr Bruder Ze'ev waren nie in Deutschland, wohin ihr Vater seit den 1980er Jahren zu vielen Vorträgen und Tagungen wieder gereist ist: Shulamit, weil es nicht mit ihrer Ideologie vereinbar ist, der Sohn, heute selbst in einer hohen Position im Schulwesen, weil er sich sowohl von allem Jeckischen als auch von Deutschland weiterhin fern hält:

Beispiel 15: Ze'ev Walk [76min 44s - 78min. 10s]

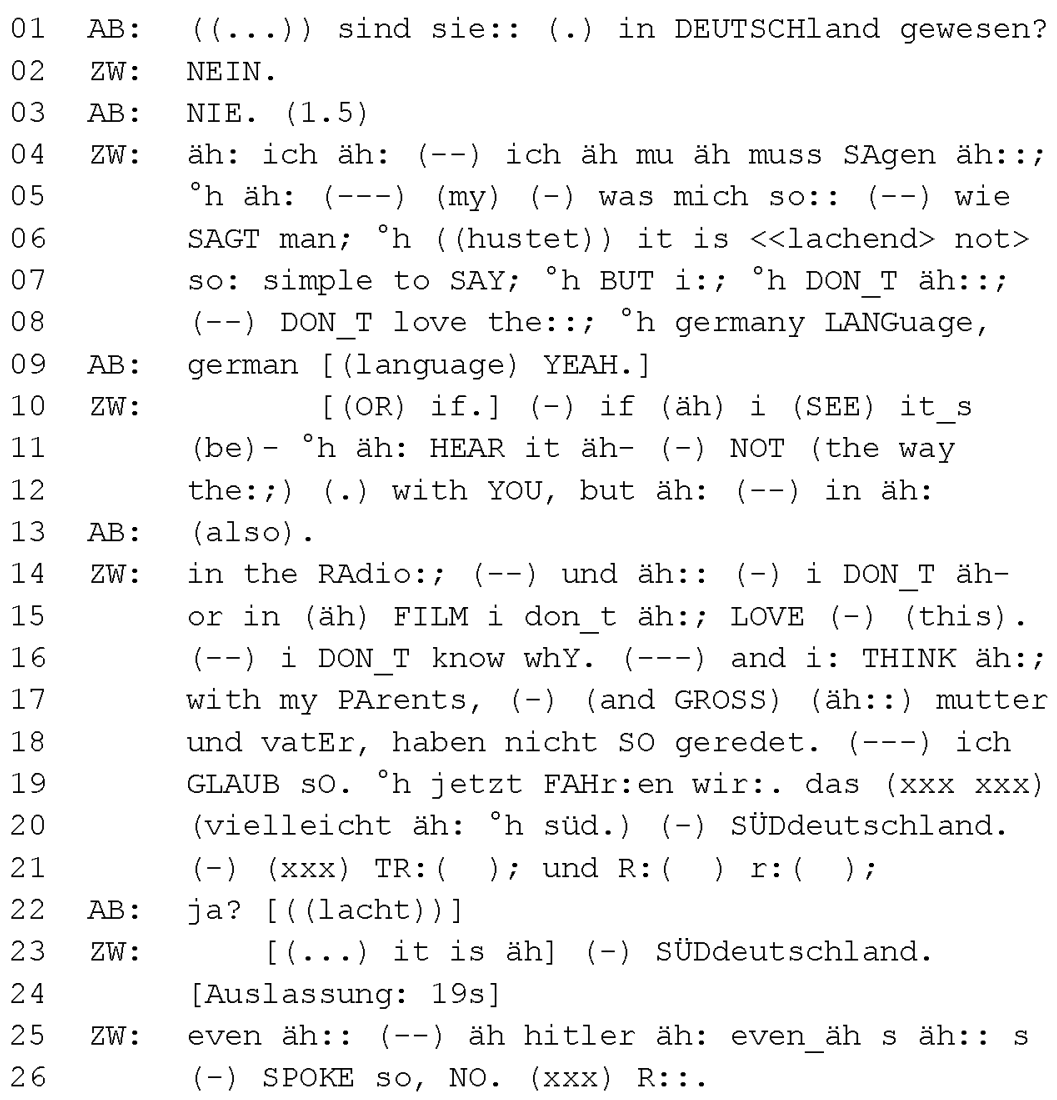


Das Code-Switching in Zeile 6, gleich mehrfach flankiert (flagged) von metasprachlichen Kommentaren (Z. 5 f:: wie sagt man, Z. 6f.: it is not so simple to say) und entschuldigendem Lachen (Z. 6), ist ein bedeutungsvoller Kontextualisierungshinweis: ${ }^{95}$ Es drückt sowohl die Distanz des Sprechers zu der von ihm bisher benutzten Sprache aus als auch das Bemühen, die Gesprächspartnerin nicht durch diese Äußerung in ihrer eigenen Sprache zu kränken und die gute Gesprächsatmosphäre dadurch zu gefährden. Die Abneigungserklärung wird sozusagen in eine andere Sprache ,ausgelagert“. 96 - Walk junior fährt dann noch (auf Deutsch) fort, dass er sich - im Gegensatz zu dem verbreiteten jüdischen Interesse an Stammbaumforschung - auch nicht in die Familiengeschichte (in Deutschland) vertiefe, was angesichts der Tätigkeiten seines Vaters für die deutsch-jüdische Geschichte im Leo Baeck Institut für diesen schwer verständlich wäre, weshalb er es ihm nicht so direkt sagt. $^{97}$

Seine Zwillingsschwester Shoshana und ihr Mann haben in den letzten Jahren Deutschland nun doch mehrfach auf der Durchreise besucht, va. die Heimatstadt ihrer Mutter, Düsseldorf:

\section{Beispiel 16: Shoshana Stahl [79min 23s - 79min 54s]}

$A B:((\ldots))$ wenn sie jetzt in DEUTSCHland sind,

25 Zu dieser viel behandelten Funktion von Code-Switching vgl. kurz Riehl (2009, S. 24 f.).

96 Zum Hintergrund der negativen Konnotationen mit der deutschen Sprache als „Sprache der Mörder" vgl. nochmals Anmerkung 55. Eindrucksvoll und für mehrere Generationen gültig beschreibt Amos Oz (2005) seine persönlichen Kindheitserinnerungen an die deutsche Sprache und die (auch bei vielen anderen) damit verbundenen Konnotationen, die hauptsächlich aus Hollywood-Filmen über den Zweiten Weltkrieg stammten: „Aus dem Mund eiskalter, bösartiger Nazis in Wehrmachtsuniformen oder in schwarzen SS- und Gestapo-Uniformen hörten wir dann, wieder und wieder, jenes Dutzend gebellter deutscher Wörter, bei denen es mir heute noch kalt über den Rücken läuft: raus, schnell, Achtung, kaputt, Zug, Eisenbahn, balt! Und jawobll" (ebd., S. 16).

97 Dass gerade Kinder von Eltern, die sich noch oder wieder viel mit der deutsch-jüdischen Geschichte beschäftigen und sich in diesem Kontext auch häufig wieder beruflich in Deutschland aufgehalten haben, einen besonderen Widerstand gegen eigene Kontakte zum Herkunftsland der Eltern entwickelt haben, habe ich mehrfach (nicht nur bei Religiösen, siehe Anm. 80) erlebt, am krassesten durch die einzige Ablehnung eines Interviews bei dem Sohn eines besonders aktiv um Verständigung bemühten Gesprächspartners der 1. Generation. Gabriele Rosenthal scheint bei ihren Interviews in Israel va. bei der 2. Generation in Kibbuzim Anfang der 1990er Jahre häufig Erfahrungen mit einer fast aggressiv ablehnenden Haltung gegenüber den „europäischen“ Eltern gemacht zu haben (vgl. Rosenthal 2006). Dies trifft für meine Interviews seit 1999 als heutige Einstellung nicht mehrheitlich zu, sicher nicht zuletzt wegen des fortgeschrittenen Alters der Interviewten und besonders ihrer Eltern, was vielfach zu einem größeren Verständnis für die Probleme der Eltern und einer positiveren Sicht auf das Elternhaus geführt hat, siehe unten 3.4. (Vgl. auch Betten 2010, 2011c und besonders 2007b: siehe Anm. 85.) 


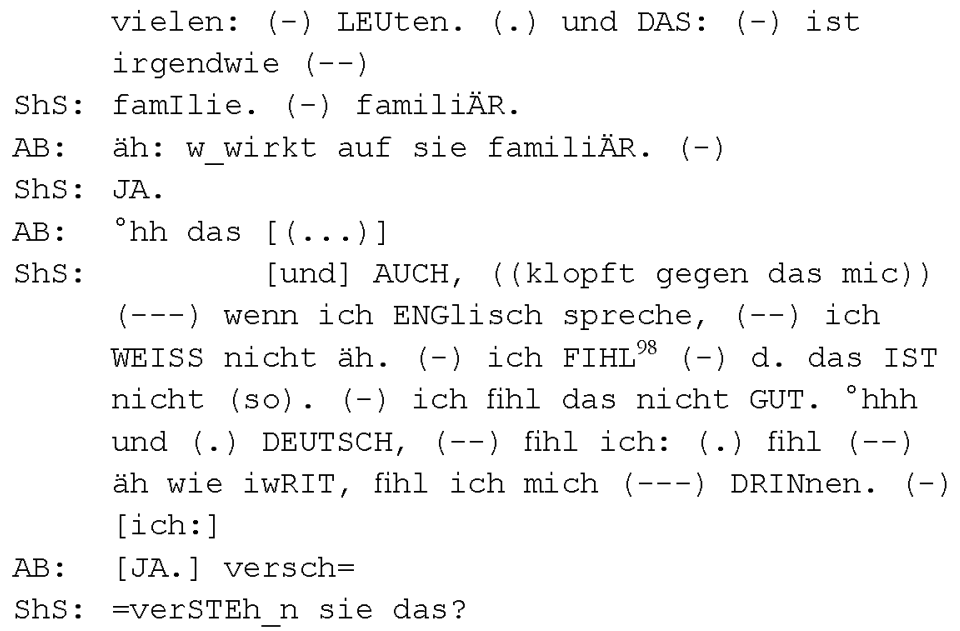

So, wie sie die deutsche Sprache als familiär bezeichnet (Z. 5), als Sprache, in der sie sich, wie im Hebräischen, drinnen fühlt (Z. 14), ${ }^{99}$ haben es auch andere Interviewpartner/innen der 2. Generation aus ihrer heutigen Empfindung ausgedrückt. Deutsch - das ist Oma, das ist Opa, das ist die ganze Familie, sagte eine andere. ${ }^{100}$ Die Assoziation mit der Familiensprache, an die die Jeckeskinder heute doch oft wieder nostalgisch positiv zurückdenken, darf aber nicht mit generell positiven Gefühlen für alles Deutsche verwechselt werden!

Diejenigen Angehörigen der 2. Generation, die noch Deutsch sprechen können, haben auf Reisen in den letzten Jahren z.T. auch eigene Bekannte und Freunde gewonnen, und einige von ihnen wollen sogar bewusst Brücken bauen zwischen den jungen Generationen aus ihrem Land und den

98 Es handelt sich um die für Iwrit-Sprecher typische Entrundung eines deutschen Umlauts, hier beim Verb füblen. - Allgemein zu (phonetischen und anderen) Interferenzerscheinungen aus dem Hebräischen, die heute bei fast allen Sprecher/inne/n der 2. Generation anzutreffen sind, obwohl sie sie in der ersten Phase des Erwerbs des Deutschen nicht aufgewiesen haben dürften, vgl. Purschke (1998). Geschah diese Überlagerung der deutschen Aussprache durch das im Leben der 2. Generation immer dominanter werdende Hebräische auch in der Regel unbewusst, so gibt es doch auch subtile Einzelbeobachtungen von Sprecher/inne/n zur psychologischen Dimension z.B. eines hebräischen Akzents im Deutschen, aber auch eines deutschen Akzents im Hebräischen: vgl. dazu den Theaterwissenschaftler Tom Lewy in Betten (2010, S. 43).

99 Zu dieser Bezeichnung, die allgemein von Mehrsprachigen für die Sprachen, in denen sie sich „zu Hause“ fühlen, gern benutzt wird (siehe Betten 2011a, S. 67, von dieser Stelle ausgehend), vgl. Leonardi (2010, S. 327 ff.) zur Verwendung der konzeptionell „räumlichen Metaphern DRAUSSEN-DRINNEN“ mit Beispielen aus den Interviews mit der 1. Generation (dort va. verwendet für den „Gegensatz zwischen Integration und Bruch“ im sprachlichen und kulturellen Bereich).

100 Siehe die Beispieltexte von Gila Friedmann in Betten (2011b, S. 226 f.). 
Herkunftsländern ihrer Eltern. ${ }^{101}$ Zu ihnen gehört Irit Ovadia, geb. Alsberg. Gerade sie hat zwar einen orientalischen Juden geheiratet, was sie in interessanter Weise, wenngleich ohne deutliche Evaluation kommentiert: Man muss aber nicht alle sein wie die Alsberg. Das war mir gleich klar. Und ich werde nie so einen Alsberg wieder beiraten. ${ }^{102}$ Aber sie verehrt ihren Vater nicht zuletzt, weil er sich ganz früh für Aussöhnung einsetzte, und sie auch mit der ersten israelischen Studentengruppe 1966 nach Deutschland schickte. Dass sie erst damals, in Deutschland, mit den Gleichaltrigen zum ersten Mal über den Holocaust diskutierte, ist durchaus kein seltenes Phänomen. Von der Zeit ihres Vaters im Konzentrationslager unmittelbar vor der Emigration erfuhr allerdings erst der Enkel von Paul Alsberg Genaueres. Seine Tochter hat in seinem Geiste Jugendaustausch und Städtepartnerschaften angebahnt. Und nur in der Geburtsstadt ihres Vaters Wuppertal bekommt sie immer noch Herzklopfen, obwohl sie vorausschickt: Ich bin hier geboren. Ich hab nix mit Wuppertal qu tun (Z. $7 \mathrm{ff}$.$) :$

\section{Beispiel 17: Irit Ovadia [81min 8s - 81min 56s]}

01 IO: GUCK mal, ich bin frEmd in ROsenheim. (--) ich

02 war schon ZIGmal in rosenheim. (-) macht mir

$A B:$ JA. (---) JEdes mal?

NIX rosenheim. (--) BAYern. (--) ich kOmm nach wUppertal, (--) ich krea (-) krIEge HERZklopfen.

IO: JEdes mal. (1.5) und (-) SAG mir nicht. ich bin hier geBoren. ich hab NIX mit wuppertal $\mathrm{zu}$ tun. (-) ${ }^{\circ}$ hh aber (--) ich kriege HERZklopfen. (-) wenn ich in wuppertal bin. ${ }^{\circ}$ hh vielleIcht sind es die FREUNde; viellelcht sind das ${ }^{\circ} \mathrm{hh}$ das: GANze, (.) viellelcht ist es weil als KIND; in der roonstraße wir waren im HAUS; ${ }^{\circ} \mathrm{h}$ bis HEUte gehe ich noch zur roonstraße. ${ }^{\circ} \mathrm{hh}$ das (-) mir das HAUS anzusehen. ${ }^{\circ}$ hh äh wir geh_n zum FRIEDhof. (-) das ist KLAR. ich bin in WUPpertal, (-) ich gehe zum FRIEDhof. (--) die faMllie liegt dort. die GANze familie dort. 'hhh und (-) ich MEIne, (---) für MICH, (-) in wuppertal zu SEIN, (.) ist was (besonderes). ( (..))

\footnotetext{
101 Besonders ergiebig zu diesem Thema ist das Interview mit dem im Kibbuz groß gewordenen Reuven Barak (Deutsches Spracharchiv, Korpus ISZ, siehe Anm. 30).

102 Nicht publizierte Stelle aus dem Interview.
} 


\subsection{Schlussgedanken}

Die Interviews aus Israel bieten unter vielem anderen sehr differenzierte und unterschiedliche Beispiele für eine durch Traumatisierung und Kulturbruch erzwungene Identitätsumbildung in der 1. Generation von Migranten und die Auswirkungen einer gesellschaftlich stigmatisierten Herkunftsidentität in der 2. Generation. Bei der 1. Generation hatte dies kaum Folgen für die meist ausgezeichnete Bewahrung der Erstsprache Deutsch, häufig jedoch auf den (mangelhaften) Erwerb der Zweitsprache Iwrit. Die 2. Generation hingegen bewahrte Deutsch als Erstsprache in den meisten Fällen nur eingeschränkt bis stark relikthaft, va. mit starker Reduzierung der aktiven Sprechkompetenz, erwarb jedoch die zweite Sprache Iwrit in allen Fällen perfekt.

Für den Rückblick auf die Identitätsentwicklung ist zu berücksichtigen, dass die 2. Generation zur Aufnahmezeit noch wesentlich jünger war als ihre Eltern, dass also noch keine abgeschlossene Entwicklung vorliegt, was auch für die Einstellungen zur Herkunftskultur der Eltern und die Bereitschaft, sich mit ihr auseinanderzusetzen und sie als Teil der eigenen Identität anzuerkennen, gilt. Es gibt viele Hinweise, dass hier noch weitere Wandlungsprozesse im Gang sind. Dazu einige Beispiele: In den letzten Jahren ist ein erhöhtes Interesse an (oftmals ersten) Reisen nach Deutschland (bevorzugt nach dem derzeit äußerst populären Berlin) zu beobachten, und zwar auch bei Interviewpartner/inne/ $\mathrm{n}$, die dies vor wenigen Jahren noch ablehnten. Die Anwendung eigener Sprachkenntnisse ist durchaus ein Teil dieser neuen Erfahrungssuche (zumal in Israel oft keine Familienangehörigen mehr am Leben sind, mit denen man die Erstsprache noch sprechen könnte). - Gegen alle Erwartungen der 1. Generation haben die (jetzt oft selbst schon pensionierten) Jeckeskinder sich entschlossen, die von ihren Eltern vor 80 Jahren gegründeten Vereine und sozialen Einrichtungen (va. Altersheime) der ehemaligen „Einwanderer aus Mitteleuropa" und sogar ihre Zeitung weiterzuführen, wenngleich nun das meiste in hebräischer Sprache abläuft. ${ }^{103}$ Und dieselben Kinder, die sich in ihrer Jugend wegen der Besonderheiten ihrer Elternhäuser schämten, sind heute interessiert, die Leistungen der jeckischen Einwanderung, der 5. Alija, für den Aufbau Israels ins rechte Licht zu rücken. Dies bedeutet nicht unbedingt auch neue Sym-

103 Die Zeitung nennt sich seither nicht mehr, ,Mitteilungsblatt“ sondern Yakinton (Name einer Blume, beabsichtigt ist die Klangassoziation zu ,Jecke', eng-. Schreibung, Y'rekke). Zum unerwartet großen Interesse an der ersten von Angehörigen der 2. Generation in Jerusalem veranstalteten Konferenz über die Jeckes vgl. Zimmermann/Hotam (Hg.) (2005). Zu einem Jubiläumstreffen der Jeckes, das der aus Deutschland stammende Industrielle Stef Wertheimer 2011 auf dem Gelände seines Industrieparks in Tefen veranstaltete (wo er u.a. auch ein „Museum of the German Speaking Jewry ${ }^{c c}$ eingerichtet hat), fanden sich fast 7.000 Menschen ein, überwiegend Angehörige der 2. Generation. 
pathie für deren Herkunftsländer selbst - kann aber, wie in jüngster Zeit bei der 3. Generation zu beobachten, die keine deutschen Sprachkenntnisse, aber ein neues Interesse an ihrem Erwerb hat (als einer Fremdsprache, die aber doch merkwürdig vertraut ist), durchaus zu neuen Formen der Auseinandersetzung mit der Herkunftskultur und dem Herkunftsland der eigenen Familien führen.

\section{Anhang: Kurzbiographien der Interviewpartner/innen}

\section{Die 1. Generation}

Betti Alsberg (geb. Keschner), *1920 in Hattingen

Lyzeum, 1937/38 Studien am Jüdisch-Theologischen Seminar in Breslau und Vorbereitungskurse für das Lehrerseminar in Jerusalem; 1939 Emigration mit ihrem Ehemann nach Palästina; Abschluss des Lehrerseminars, Schwesternschule, Krankenschwester, Buchhandel, Volontärarbeiten.

Aufnahme: Anne Betten, Jerusalem 1994 [zus. mit Ehemann Paul Avraham].

Dr. Paul Avraham Alsberg (ehem. Paul Alfred Alsberg), *1919 in Elberfeld Abitur in Wuppertal, 1937/38 Studium am Jüdisch-Theologischen Seminar in Breslau, nach den Novemberpogromen 1938 zwei Monate im Konzentrationslager Buchenwald; 1939 Emigration mit seiner Frau Betti nach Palästina; Geschichtsstudium, 1942-47 u.a. Holzfabrikation, 1947/48 Militär, Archivar am Zionistischen Zentralarchiv, Promotion, 1957 Leiter des Staatsarchivs, 1971-1990 Staatsarchivar von Israel, Professor; vielfältige ehrenamtliche Führungstätigkeiten (u.a. für den Irgun Olej Merkas Europa), Nachlassverwalter Else Lasker-Schülers; gilt als ein Wegbereiter der dt.-jüd. Verständigung: Aufnahme: Anne Betten, Jerusalem 1994 [zus. mit Ehefrau Betti].

Dr. Yehoshua Arieli (ehem. Yehoshua Löbl), *1916 in Karlsbad Gymnasium in Karlsbad; 1931 mit den Eltern nach Palästina; Landwirtschaftsschule (Ben Shemen), einige Jahre im Kibbuz, danach u.a. Arbeit in Autowerkstatt, 1937 externe Matura, Beginn eines Studiums (Geschichte/Philosophie), im 2. Weltkrieg im engl. Militär (1941-45 in dt. Kriegsgefangenschaft), Hagana, Offizier der isr. Armee; 1949 Wiederaufnahme des Studiums, 1951-53 Harvard-Stipendium, Promotion; Universitätsprofessor für Geschichte an der Hebr. Univ. Jerusalem; 1993 Israelpreis; Publikationen auf Hebr., Engl., Dt.; gilt als „Doyen of American History and American Studies" in Israel.

Aufnahme: Miryam Du-nour, Jerusalem 1991.

Ada Brodsky (geb. Neumark), ${ }^{*} 1924$ in Frankfurt/O.

Gymnasium in Frankfurt/O; 1938 nach Palästina mit der Jugendalija (2 Jahre Ben Shemen), Abitur in Jerusalem, Studium (Judaismus/Engl. Literatur abgebrochen, Wechsel zur Musikakademie), Unterricht an Schulen/Akademien, Musikredakteurin beim Radio, preisgekrönte Übersetzerin dt. Lyrik u. Prosa ins Hebr. (1994 Goethe-Medaille), Publikationen auf Hebr. (u.a. Rilke-Übersetzung und -Monographie).

Aufnahme: Miryam Du-nour 1991. 
Dr. Joseph Walk, $* 1914$ in Breslau

Abitur in Breslau, 1932-33 Jüd. Lehrersem. Köln, Lehrer an jüd. Schulen in Breslau, Umschichtung (Landwirtschaft); 1936 Emigration nach Palästina; fünf Jahre Lehrer und Erzieher für die rel. Jugendalija und bis 1952 Lehrer im Moshav Sde Ja'akov, Schulinspektor, Dozent an Lehrerseminaren; daneben Studium (Pädagogik/Jüd. Geschichte der Neuzeit), 1964-81 Dozent für Pädagogik an der Bar Ilan-Universität, Mitarbeiter von Yad Vashem, Direktor des Leo Baeck Instituts, nach Pensionierung Vizepräsident des Vorstands und freier Forscher; Mitbegründer und zeitw. Leiter der rel.-zionistischen Friedensbewegung „Os we Schalom“, 1996 Buber-Rosenzweig-Medaille der Gesellschaft für Christl.-Jüd. Zusammenarbeit.

Aufnahme: Anne Betten, Jerusalem 1991.

Dr. Leni Yahil (ehem. Hoffmann, geb. Westphal), ${ }^{* 1912}$ in Düsseldorf

Abitur in Potsdam, ein Jahr Studium (Geschichte) in München u. Berlin, danach Hochschule für die Wiss. des Judentums in Berlin; 1934 Emigration nach Palästina; 1 Jahr Kibbuz (Gründungsgruppe von Hasorea), Fortsetzung des Studiums in Jerusalem (Geschichte/Literatur), journalistische u. politische Tätigkeiten (u.a. 1947 und 1953/54 in Dtschl., in Begleitung der polit. Missionen ihres Mannes), Promotion, Professorin für mod. Jüd. Geschichte in Haifa, Gastprofessuren in USA (Schwerpunkt Holocaust-Forschung, Hauptwerk Shoah 1987 auf Hebr., 1990 auf Engl., 1998 auf Dt.).

Aufnahme: Miryam Du-nour, Jerusalem 1993.

\section{Die 2. Generation}

Shulamit Melamed (geb. Walk), *1939 in Sde Ja'akov, verheiratet, 7 Kinder 1947 ein Jahr in Belgien (frz. Schulunterricht), wo ihre Eltern Kinder aus Konzentrationslagern auf die Einreise nach Israel vorbereiteten; weitere Schulzeit im Moshav Sde Ja'akov, Gymnasium in Jerusalem, Lehrerseminar, 15 Jahre Lehrerin, Pädagogik- und Psychologie-Studium; als Rabbanit im ultra-orthodoxen Umfeld ihres Ehemanns Rabbi Melamed in der rel. Siedlung Beit El tätig; politische Aktivistin, als Gründerin des illegalen ultrarechts-nationalen Radiosenders Arutz (Kanal) 7 und Betreiberin einer Internetzeitung unter den Vorschlagskandidat/inn/en für den israclischen Medienpreis 2012. Aufnahme: Anne Betten, Jerusalem 2005.

Irit Ovadia (geb. Alsberg), ${ }^{*} 1946$ in Jerusalem, verheiratet, 3 Kinder Gymnasium in Jerusalem; nach dem Militärdienst 1966 Teilnahme am 1. isr.-dt. Studententreffen in Paderborn, danach 8 Monate in den USA, Englisch-Studium, EnglischLehrerin, administrative Leiterin eines Konservatoriums in Be'er Sheva; Aufbau von Jugendaustauschprogrammen mit Deutschland, u.a. Reisen mit dt.-isr. Studentengruppen in Konzentrationslager, viele Kontakte mit der Heimatstadt des Vaters Wuppertal. Aufnahme: Anne Betten, Omer (bei Be'er Sheva) 1999.

Shoshana Stahl (geb. Walk), ${ }^{*} 1937$ in Sde Ja'akov [Zwillingsschwester von Ze'ev Walk], verheiratet, 4 Kinder

Schulzeit im Moshav, Kindergärtnerinnenseminar, Arbeit in Kibbuzverwaltung. Mit ihrem in Holland geborenen Ehemann, der als Kind von 1942-1945 in den Konzentrationslagern Westerbork, Ravensbrück und Bergen-Belsen war, seit 1994 einige kurze Deutschlandbesuche.

Aufnahme: Anne Betten, Jerusalem 1999. 
Ze'ev Walk, *1937 in Sde Ja'akov [Zwillingsbruder von Shoshana Stahl], verheiratet, 6 Kinder

Schulzeit im Moshav und in Haifa, danach Ideal vom Leben im Kibbuz einige Jahre zu verwirklichen gesucht, Verlassen des Kibbuz, da keine Erlaubnis zum Studium; Lehrerseminar, Lehrer, Erziehungs- und Schulberater.

Aufnahme: Anne Betten, Jerusalem 1999.

\section{Literatur}

Bar-On, Dan (2004): Erzähl dein Leben! Meine Wege zur Dialogarbeit und politischen Verständigung. Hamburg.

Ben-Rafael, Eliezer (1994): Langugage, identity and social division. The case of Israel. (= Oxford Studies in Language Contact). Oxford u.a.

Benz, Wolfgang (Hg.) (1996): Die Juden in Deutschland 1933-1945. Leben unter nationalsozialistischer Herrschaft. (= Veröffentlichung des Instituts für Zeitgeschichte; Beck's historische Bibliothek). 4., unveränd. Aufl. München.

Betten, Anne (Hg.) (1995): Sprachbewahrung nach der Emigration - Das Deutsch der 20er Jahre in Israel. Teil I: Transkripte und Tondokumente. Mit CD. Unter Mitarbeit von Sigrid Graßl. (= Phonai 42). Tübingen.

Betten, Anne (2000a): „Vielleicht sind wir wirklich die einzigen Erben der Weimarer Kultur“. Einleitende Bemerkungen zur Forschungshypothese „Bildungsbürgerdeutsch in Israel ${ }^{c c}$ und zu den Beiträgen dieses Bandes. In: Betten/Du-nour ( $\mathrm{Hg}$ ), S. 157-181.

Betten, Anne (2000b): Satzkomplexität, Satzvollständigkeit und Normbewußtsein. Zu syntaktischen Besonderheiten des Israel-Corpus. In: Betten/Du-nour (Hg.), S. 217 270 .

Betten, Anne (2007a): Die Sprachinsel der Jeckes. In: Dachs, Gisela (Hg.): Sprachen. (= Jüdischer Almanach des Leo-Baeck-Instituts). Frankfurt a.M., S. 33-42.

Betten, Anne (2007b): Rechtfertigungsdiskurse. Zur argumentativen Funktion von Belegerzählungen in narrativen Interviews. In: Redder, Angelika (Hg.): Diskurse und Texte. Festschrift für Konrad Ehlich zum 65. Geburtstag. (= Stauffenburg Festschriften). Tübingen, S. 105-116.

Betten, Anne (2009): Berichten - Erzählen - Argumentieren revisited: Wie multifunktional sind die Textsorten im autobiographischen Interview? In: Taterka, Thomas/ Lele-Rozentãle, Dzintra/Pavĩdis, Silvija (Hg): Am Rande im Zentrum. Beiträge des VII. Nordischen Germanistentreffens, Riga, 7.-11. Juni 2006. Berlin, S. 227-243.

Betten, Anne (2010): Sprachbiographien der 2. Generation deutschsprachiger Emigranten in Israel: Zur Auswirkung individueller Erfahrungen und Emotionen auf die Sprachkompetenz. In: Franceschini, Rita (Hg.), S. 29-57.

Betten, Anne (2011a): Zusammenhänge von Sprachkompetenz, Spracheinstellung und kultureller Identität - am Beispiel der 2. Generation deutschsprachiger Migranten in Israel. In: Thüne, Eva-Marie/Betten, Anne (Hg.): Sprache und Migration. Linguistische Fallstudien. (= Lavori interculturali sul Tedesco 4). Rom, S. 53-87. 
Betten, Anne (2011b): Sprachheimat vs. Familiensprache. Die Transformation der deutschen Sprache von der 1. zur 2. Generation der Jeckes. In: Kohlross, Christian/ Mittelmann, Hanni ( $\mathrm{Hg}$ ): Auf den Spuren der Schrift. Israelische Perspektiven einer internationalen Germanistik. (= Conditio Judaica 80). Berlin/Boston, S. 205-228.

Betten, Anne (2011c): Die Akkulturation der deutschsprachigen Immigranten in Israel: Berichte aus heutiger Perspektive. In: Azuélos, Daniel (Hg.): Alltag im Exil. Würzburg, S. 59-78.

Betten, Anne (i.Dr.): Die erste Reise zurück nach Deutschland. Thematische Fokussierung und Perspektivierung in Erzählungen jüdischer Emigrant/inn/en. In: Deppermann, Arnulf/Hartung, Martin (Hg.): Gesprochenes und Geschriebenes im Wandel der Zeit. [Festschrift für Johannes Schwitalla.] Mannheim.

Betten, Anne (ersch.demn.): „Aber die Schwierigkeit hier war nun eben das Schreiben“ - Die Sprache als Barriere zwischen erwählter und ersehnter Identität. In: Horch, Otto/Mittelmann, Hanni/Neuburger, Karin (Hg.): Exilerfahrung und Konstruktionen von Identität 1933 bis 1945 . Berlin/Boston.

Betten, Anne/Du-nour, Miryam (Hg.) (2000): Sprachbewahrung nach der Emigration - Das Deutsch der 20er Jahre in Israel. Teil II: Analysen und Dokumente. Mit CD. Unter Mitarbeit von Monika Dannerer. (= Phonai 45). Tübingen.

Betten, Anne/Du-nour, Miryam (2004): Wir sind die Letzten. Fragt uns aus. Gespräche mit den Emigranten der dreißiger Jahre in Israel. Unveränd. Neuaufl. der Ausg. von 1995. Gießen.

Braese, Stephan (2010): Eine europäische Sprache. Deutsche Sprachkultur von Juden 1760-1930. Göttingen.

Brodsky, Ada/Neumark, Eldad (2000): Nach Hause vertrieben. Geschichte einer Kindheit in Hitler-Deutschland. 2 Audio-CDs. Augsburg.

Busch, Brigitta (2010): Die Macht präbabylonischer Phantasien. Ressourcenorientiertes sprachbiographisches Arbeiten. In: Franceschini, Rita (Hg), S. 58-82.

Diner, Dan (2005): Jeckes - Ursprung und Wandel einer Zuschreibung. In: Zimmermann, Moshe/Hotam, Yotam (Hg.): Zweimal Heimat. Die Jeckes zwischen Mitteleuropa und Nahost. Frankfurt a.M., S. 100-103.

Du-nour, Miryam (2000a): Sprachbewahrung und Sprachwandel unter den deutschsprachigen Palästina-Emigranten der 30er Jahre. (Anhang: Modernes Hebräisch - die vorherrschende Sprache innerhalb der jüdischen Gemeinschaft in Palästina). In: Betten/Du-nour (Hg.), S. 182-216.

Du-nour, Miryam (2000b): Sprachenmischung, Code-Switching, Entlehnung und Sprachinterferenz. Einflüsse des Hebräischen und Englischen auf das Deutsch der fünften Alija. In: Betten/Du-nour (Hg.), S. 445-477.

Eller, Nicole (2010): „I'm still Bohemian minded!c Eine Untersuchung ausgewählter Sprachbiographien von Sprecherinnen und Sprechern deutschböhmischer Varietäten in aller Welt. In: Franceschini, Rita (Hg.), S. 151-166.

Erel, Shlomo (1983): Neue Wurzeln. 50 Jahre Immigration deutschsprachiger Juden in Israel. Gerlingen. 
Fix, Ulla (2010): Sprachbiographien als Zeugnisse von Sprachgebrauch und Sprachgebrauchsgeschichte. Rückblick und Versuch einer Standortbestimmung. In: Franceschini, Rita (Hg.), S. 10-28.

Franceschini, Rita (Hg.) (2010): Sprache und Biographie (Themenheft). In: Zeitschrift für Literaturwissenschaft und Linguistik 40, 160.

Franceschini, Rita (2010): Einleitung. In: Franceschini, Rita (Hg.), S. 7-9.

Franceschini, Rita/Miecznikowski, Johanna (Hg.) (2004): Leben mit mehreren Sprachen/Vivre avec plusieurs langues: Sprachbiographien/Biographies langagières. (= Transversales - Langues, Sociétés, Cultures et Apprentissages 9). Bern u.a.

Hansen-Schaberg, Inge (2006): „Exil als Chance“. Voraussetzungen und Bedingungen der Integration und Akkulturation. In: Krohn (Hg.), S. 183-197.

Inowlocki, Lena (1999): Wenn Tradition auf einmal mehr bedeutet: Einige Beobachtungen zu biographischen Prozessen der Auseinandersetzung mit Religion. In: Apitzsch, Ursula (Hg.): Migration und Traditionsbildung. Wiesbaden, S. 76-90.

Jessen, Caroline (2011): Keine leichten Pakete: Ada Brodsky. Jerusalem. (= Deutschisraelisches Buchprojekt, „Einzelschicksale, die Geschichte erzählen", hrsg. v. Simone Lenz, Goethe Institut Jerusalem). Internet: www.goethe.de/ins/il/jer/pro/klp/Buchprojekt _Brodsky_web.pdf (Stand 10.07.2012).

Kremer, Arndt (2007): Deutsche Juden - deutsche Sprache. Jüdische und judenfeindliche Sprachkonzepte und -konflikte 1893-1933. (= Studia Linguistica Germanica 87). Berlin/New York.

Kresic, Marijana (2006): Sprache, Sprechen und Identität: Studien zur sprachlich-medialen Konstruktion des Selbst. München.

Krohn, Claus-Dieter (Hg) (2006): Kindheit und Jugend im Exil. Ein Generationenthema. Hrsg. im Auftrag der Gesellschaft für Exilforschung. (= Exilforschung 24). München.

Leonardi, Simona (2010): Wie Metaphern zur Konstruktion narrativer Identitäten beitragen: Eine Metaphernanalyse im Interviewkorpus „Emigrantendeutsch in Israel“. In: Palander-Collin, Minna et al. ( $\mathrm{Hg}$ ): Constructing identity in interpersonal communication/Construction identitaire dans la communication interpersonelle/Identitätskonstruktionen in der interpersonalen Kommunikation. (= Mémoires de la Société Néophilologique de Helsinki 81). Helsinki, S. 323-336.

Lucius-Hoene, Gabriele/Deppermann, Arnulf (2002): Rekonstruktion narrativer Identität. Ein Arbeitsbuch zur Analyse narrativer Interviews. Opladen.

Maiwald, Salean A. (2008): Aber die Sprache bleibt. Begegnungen mit deutschstämmigen Juden in Israel. Berlin.

Majer, Martina (2009): Erzählen gegen das Vergessen: Interviews mit jüdischen Emigrant/inn/en. Linguistische Betrachtungen zur Interdependenz von Intention, Textsortenwahl und Identität. Diss. Salzburg. [Publikation i.Vorb.].

Malo, Markus (2009): Behauptete Subjektivität. Eine Skizze zur deutschsprachigen jüdischen Autobiographie im 20. Jahrhundert. (= Conditio Judaica 74). Tübingen. 
Matthes, Olaf (2000): James Simon. Mäzen im Wilhelminischen Zeitalter. (= Bürgerlichkeit, Wertewandel, Mäzenatentum 5). Berlin.

Oppenrieder, Wilhelm/Thurmair, Maria (2003): Sprachidentität im Kontext von Mehrsprachigkeit. In: Janich, Nina/Thim-Mabrey, Christiane ( $\mathrm{Hg}$ ): Sprachidentität Identität durch Sprache. (= Tübinger Beiträge zur Linguistik 465). Tübingen, S. 39-60.

Oz, Amos (2005): Israel und Deutschland. Vierzig Jahre nach Aufnahme diplomatischer Beziehungen. (= Sonderband edition suhrkamp) Frankfurt a.M.

Portz, Renate (1982): Sprachliche Variation und Spracheinstellungen bei Schulkindern und Jugendlichen: eine empirische Untersuchung in Norwich/England. (= Tübinger Beiträge zur Linguistik 184). Tübingen.

Purschke, Kerstin (1998): Mehrsprachigkeit im Generationenwechsel. Zum Sprachgebrauch der Zweiten Generation deutschsprachiger Gruppen in Israel. Hausarbeit zum 1. Staatsexamen. Kiel.

Riehl, Claudia Maria (2009): Sprachkontaktforschung. Eine Einführung. 2., überarb. Aufl. (= Narr-Studienbücher). Tübingen.

Rosenthal, Gabriele (1995): Erlebte und erzählte Lebensgeschichte. Gestalt und Struktur biographischer Selbstbeschreibungen. Frankfurt a.M.

Rosenthal, Gabriele (2006): Israelische Familien von jugendlichen ZwangsemigrantInnen aus Deutschland. Zu den transgenerationellen Folgen einer Emigration ohne Eltern und Geschwister. In: Krohn (Hg.), S. 231-249.

Rosenthal, Gabriele/Völter, Bettina/Gilad, Noga (1999): Folgen der Zwangsemigration über drei Generationen. Israelische Familien mit Großeltern aus Deutschland. In: Apitzsch, Ursula ( $\mathrm{Hg}$ ): Migration und Traditionsbildung. Wiesbaden, S. 45-75.

Schmid, Monika S. (2002): First language attrition, use and maintenance. The case of German Jews in anglophone countries. (= Studies in Bilingualism 24). Amsterdam/Philadelphia.

Schütze, Fritz (1982): Narrative Repräsentation kollektiver Schicksalsbetroffenheit. In: Lämmert, Eberhard (Hg.): Erzählforschung. Ein Symposion. (= Germanistische Symposien-Berichtsbände 4). Stuttgart, S. 568-590.

Schweiger, Teresa (2011): „Man war vor 60 Jahren Deutscher jüdischen Glaubens und heute bin ich Jude ${ }^{c}:$ Pronominale Alternation als Ausdruck narrativer Identitäten in ausgewählten Interviews mit deutschsprachigen Emigrant/innen in Israel. Diss. Salzburg.

Śegev, Tom (2008): Die ersten Israelis. Die Anfänge des jüdischen Staates. Berlin.

Selting, Margret et al. (2009): Gesprächsanalytisches Transkriptionssystem 2 (GAT 2). In: Gesprächsforschung - Online-Zeitschrift zur verbalen Interaktion 10, S. 353402.

Shohamy, Elena (2005): Language rights in the multilingual society of Israel. In: Ravid, Dorit Diskin/Shyldkrot, Hava Bat-Zeev (Hg.): Perspectives on language and language development. Essays in honor of Ruth A. Berman. New York, S. 87-101. 
Straub, Jürgen (2004): Identität. In: Jaeger, Friedrich/Liebsch, Burkhard ( $\mathrm{Hg}$ ): Handbuch der Kulturwissenschaften. Bd. 1: Grundlagen und Schlüsselbegriffe. Stuttgart/Weimar, S. 277-303.

Strutz, Andrea (2006): ,... Something you can recreate without being there ${ }^{c c}$. Aspekte der Erinnerung und des intergenerationellen Gedächtnisses am Beispiel aus Ósterreich vertriebener Jüdinnen und Juden und ihrer Nachkommen. In: Krohn ( $\mathrm{Hg}$ ), S. $250-266$.

Thüne, Eva-Maria (2009): Dinge als Gefährten. Objekte und Erinnerungsgegenstände in Bettens Israel-Korpus der ersten Generation. In: Dannerer, Monika et al. ( $\mathrm{Hg}$ ): Gesprochen - geschrieben - gedichtet. Variation und Transformation von Sprache. [Festschrift zum 65. Geburtstag von Anne Betten.] (= Philologische Studien und Quellen 218). Berlin, S. 189-204.

Thüne, Eva-Maria/Leonardi, Simona (2011): Wurzeln, Schnitte, Webemuster. Textuelles Emotionspotential von Erzählmetaphern am Beispiel von Anne Bettens Interviewkorpus „Emigrantendeutsch in Israel“. In: Kohlross, Christian/Mittelmann, Hanni $(\mathrm{Hg}$.): Auf den Spuren der Schrift. Israelische Perspektiven einer internationalen Germanistik. (= Conditio Judaica 80). Berlin/Boston, S. 229-246.

Tophinke, Doris (2002): Lebensgeschichte und Sprache. Zum Konzept der Sprachbiographic aus linguistischer Sicht. In: Adamzik, Kirsten/Roos, Eva (Hg.): Biografie linguistiche/Biograhies langagières/Biographias linguisticas/Sprachbiographien (= Builletin Suisse de Linguistique Appliquée 76). Neuchâtel, S. 1-14.

Treichel, Bärbel (2004): Identitätsarbeit, Sprachbiographien und Mehrsprachigkeit. Autobiographisch-narrative Interviews mit Walisern zur sprachlichen Figuration von Identität und Gesellschaft. Frankfurt a.M. u.a.

Urban, Susanne (2006): Die Jugend-Alijah 1932 bis 1940. Exil in der Fremde oder Heimat in Erez Israel? In: Krohn (Hg.), S. 34-61.

Weinzierl, Erika/Kulka, Otto Dov (Hg.) (1992): Vertreibung und Neubeginn. Israelische Bürger österreichischer Herkunft. Mit einem Vorwort von Ernst L. Ehrlich. Wien/Köln/Weimar.

Zimmermann, Moshe/Hotam, Yotam (Hg.) (2005): Zweimal Heimat. Die Jeckes zwischen Mitteleuropa und Nahost. Frankfurt a.M. 